\title{
La intervención administrativa sobre las vías pecuarias
}

\author{
Juan Antonio Carrillo Donaire \\ Profesor Titular de Derecho Administrativo.
}

SUMARIO: I. LA INTERVENCIÓN ADMINISTRATIVA SOBRE LAS VÍAS PECUARIAS ESTÁ ORIENTADA AL CUMPLIMIENTO DE UN TRIPLE OBJETIVO: LA PRESERVACIÓN, LA ADECUACIÓN O SUFICIENCIA Y LA GARANTÍA DE USO PÚBLICO DEL DEMANIO CAÑADIEGO. II. POTESTADES DE POLICÍA DEMANIAL DIRIGIDAS A LA PRESERVACIÓN DE LA TITULARIDAD Y POSESIÓN PÚBLICA DE LAS VÍAS PECUARIAS. 1. Potestades declarativas: A) Investigación: una potestad venida a menos en la órbita del demanio cañadiego; B) La clasificación de vías pecuarias como acto singular de afectación demanial: consecuencias jurídicas; C) Deslinde y amojonamiento de vías pecuarias. El problema de los derechos de propiedad privada preexistentes. 2. Potestades ejecutorias: la recuperación de oficio y el desahucio administrativo de vías pecuarias. III. POTESTADES DIRIGIDAS A LA ADECUACIÓN (IDONEIDAD Y SUFICIENCIA) DEL DOMINIO PÚBLICO CAÑADIEGO: 1. La desafectación de vías pecuarias como potestad excepcional. Especial consideración de los tramos de vía pecuaria que atraviesen suelo urbano o urbanizable; 2. Mutación demanial por cambio de destino; 3. Modificación del trazado; 4. Creación, ampliación o restablecimiento de vías pecuarias. La virtualidad de una técnica que toma plena carta de naturaleza tras la aprobación de la LPAP: el establecimiento de servidumbres administrativas de uso público. IV. POTESTADES DESTINADAS A GARANTIZAR EL RÉGIMEN DE USOS Y SU CONTROL: 1. Tipología de usos y control preventivo de los mismos: A) Usos comunes: a) usos comunes generales; b) usos comunes especiales sujetos a autorización demanial. B) Usos privativos sujetos a concesión. 2. Control represivo de usos: A) Potestad sancionadora; B) Resarcimiento de daños. V. LA PROTECCIÓN ADICIONAL DE LAS VÍAS PECUARIAS POR RAZONES TERRITORIALES, AMBIENTALES Y CULTURALES. 


\section{LA INTERVENGIÓN ADMINISTRATIVA SOBRE LAS VÍAS PECUA- RIAS ESTÁ ORIENTADA AL CUMPLIMIENTO DE UN TRIPLE OBJE- TIVO: LA PRESERVACIÓN, LA ADECUACIÓN O SUFICIENGIA Y LA GARANTÍA DE USO PÚBLICO DEL DEMANIO CAÑADIEGO}

La tradicional función de las vías pecuarias como caminos de trashumancia, de la mayor importancia en épocas pasadas ${ }^{1}$, ha quedado muy reducida a consecuencia de la actual realidad económica y de la evolución de los sistemas de explotación de la ganadería, que han determinado el paulatino abandono de su destino primigenio en gran parte de ellas. La revitalización de estos caminos tras la decadencia económica de la ganadería trashumante pasaba por atribuir nuevos fines de las vías pecuarias que incrementaran y diversificaran su funcionalidad. Este es el verdadero leiv motif de la Ley 3/1995, de 23 de marzo, de Vías Pecuarias (en adelante LVP), que contiene la legislación básica estatal en la materia, y de las disposiciones autonómicas que la desarrollan, que han instaurado una nueva concepción de las vías pecuarias que las dota de un nuevo valor funcional y sitúa su regulación jurídica ante un "nuevo paradigma" ${ }^{2}$. De acuerdo con la vigente LVP, que consolida y amplía con determinación el tímido paso dado en este sentido por la anterior Ley de 27 de junio de $1974^{3}$, las vías pecuarias pueden ser utilizadas no sólo para el desplazamiento del ganado, que continúa siendo el uso común preferente de estas vías, sino también para usos agrarios compatibles con el pecuario, a los que se suman ahora una serie de afectaciones secundarias que conforman otros tantos usos complementarios de carácter recreativo, ecológico o cultural ${ }^{4}$. Apoyada en es-

\footnotetext{
${ }^{1}$ Sobre el auge y la decadencia de la trashumancia y la naturaleza jurídica de las vías pecuarias en perspectiva histórica nos remitimos, en general, a nuestro trabajo "Vías pecuarias" y a la bibliografía que allí se cita (publicado en el libro colectivo Derecho de los bienes públicos, Tirant lo Blanch, Valencia, 2005, pp. 531 a 588).

${ }^{2}$ En expresión de ALENZA GARCÍA, J.F., Vias pecuarias, Civitas, Madrid, 2001, p. 50.

${ }^{3}$ Que calificaba como "principal” -pero no exclusivo- el tránsito pecuario, permitiendo el uso de las vías pecuarias para usos rurales y, en especial, las comunicaciones y el paso de tractores y maquinaria agraria (art. 11 de la Ley de 1974 y art. 89 de su Reglamento).

${ }^{4} \mathrm{El}$ art. 1 de la LVP, tras definir conceptualmente las vías pecuarias como "las rutas o itinerarios por donde discurre o ha venido discurriendo tradicionalmente el tránsito ganadero", afirma, en su apdo. $3^{\circ}$, que dichas vías "podrán ser destinadas a otros usos compatibles y complementarios en términos acordes con su naturaleza y sus fines, dando prioridad al tránsito ganadero y otros usos rurales, e inspirándose en el desarrollo sostenible y el respeto al medio ambiente, al paisaje y al patrimonio natural y cultural". Con lo que la pluralidad de usos de las vías pecuarias puede sistematizarse del siguiente modo: $1^{\underline{a}}$ ) Tránsito pecuario y comunicaciones agrarias: que son -en
} 
ta dimensión medioambiental, sociocultural y de ocio que se conecta los valores que enuncian los arts. 40.1, 43.3 y 45.1 de la $\mathrm{CE}$, la red de vías pecuarias sigue prestando un servicio esencial a la trashumancia ganadera, que ahora se compatibiliza con otras dimensiones de estas vías que se conectan con sus valores naturales intrínsecos y con su aptitud para favorecer el contacto del hombre con la naturaleza ${ }^{5}$. En definitiva, el viejo paradigma según el cual las vías pecuarias eran caminos destinados únicamente al tránsito pecuario y agrícola (amenazados por la usurpación y abocados a su enajenación si dejaban de destinarse a tal fin), ha sido superado, hasta el punto de poder afirmar que si algún día dejaran de ser utilizadas por completo para los desplazamientos ga-

particular la primera- las funciones tradicionales y prioritarias de estas vías. 2 $\left.2^{a}\right)$ Función ecológica: dado el valor ecológico intrínseco de la red cañadiega, su aptitud para ser corredores ecológicos de conexión entre enclaves naturales, su consideración como franjas de protección del espacio natural, o su idoneidad como espacios de educación ambiental. $3^{\underline{a}}$ ) Ocio y esparcimiento: como dice la propia Exposición de Motivos de la LVP, "atendiendo a una demanda social creciente, las vías pecuarias pueden constituir un instrumento favorecedor del contacto del hombre con la naturaleza"; de ahí que la Ley sitúe "las vías pecuarias al servicio de la cultura y el esparcimiento ciudadano". Por ello, entre los usos complementarios de las vías pecuarias se encuentran algunas de las actividades de esa creciente demanda social: "el paseo, el senderismo o la cabalgada y otras formas de desplazamiento deportivo sobre vehículos no motorizados siempre que respeten la prioridad del tránsito ganadero" (art. 17.1 LVP) y no resulten incompatibles con "la protección de ecosistemas sensibles, masas forestales con alto riesgo de incendio, especies protegidas y prácticas deportivas tradicionales" (art. 17.3 LVP); en cuyo caso podrán ser eliminados o restringidos, de modo que la viabilidad de estos usos complementarios está supeditada a los dos anteriores usos principales (trashumancia ganadera y función ecológica). $4^{\mathrm{a}}$ ) Función histórico-cultural: las vías pecuarias son un testimonio del pasado que forma parte de nuestro patrimonio cultural que, como dice la Exposición de Motivos de la LVP, las convierte "en un legado histórico de interés capital, único en Europa", lo que determina que eventualmente puedan protegerse como bienes integrantes del patrimonio histórico.

${ }^{5}$ En este sentido, HERRÁIZ SERRANO ha señalado que los usos comunes, adicionales o complementarios, y los usos especiales y privativos de las vías pecuarias tienen un mero carácter enunciativo, por lo que son numerus apertus, Régimen jurídico de las vías pecuarias, Comares, Granada, 2000, pp. 358 y ss. De hecho, algunas Comunidades Autónomas, al desarrollar las previsiones de usos de los arts. 16 y 17 de la LVP, han contemplado otros usos distintos. Así, por ejemplo, la Ley 8/1998, de 15 de junio, de vías pecuarias de la Comunidad de Madrid, añade entre los usos comunes complementarios de las vías pecuarias actividades como "el cicloturismo, el esquí de fondo o cualquier otra forma de desplazamiento deportivo sobre vehículo no motorizado, siempre que respeten la prioridad del tránsito ganadero" (art. 32.1). Por su parte, la Ley castellano manchega 9/2003, de 20 de marzo, menciona entre los usos complementarios "la realización de actividades educativas y formativas en materia de medio ambiente y del acervo cultural" (art. 32). 
naderos, podrían mantener su condición demanial gracias a las otras funciones públicas que les reconoce la legislación vigente ${ }^{6}$.

Junto a la pluralidad funcional que se les asigna, la legislación estatal ha descentralizado la titularidad y gestión de las vías pecuarias a favor de las Comunidades Autónomas, titulares ahora del dominio público cañadiego (art. 2 LVP $)^{7}$, reforzando extraordinariamente el carácter demanial de las vías pecuarias en consonancia con la multiplicación de sus usos demaniales. A la luz de esta nueva legislación, se ha dicho con acierto que las vías pecuarias han pasado de ser un dominio público atenuado, sometido a una desamortización fáctica, a convertirse en un dominio público "superreforzado" ${ }^{8}$. Ciertamente, como tendremos ocasión de comprobar a lo largo de este trabajo, la LVP afianza las típicas notas del demanio (imprescriptibilidad, inalienabilidad, inembargabilidad) al tiempo que refuerza notablemente otras técnicas de intervención demanial.

En este último sentido, la propia LVP ofrece un criterio sistemático de la intervención administrativa en la materia al condicionar y "funcionalizar" la titularidad demanial autonómica de las vías pecuarias, desde un punto de vista teleológico, al cumplimiento de tres finalidades específicas: preservación, ade cuación y garantía de uso público. De este modo, tal y como expresamente dice la Exposición de Motivos de la LVP, la actuación de las Comunidades Autó-

\footnotetext{
${ }^{6}$ Con ello, las utilidades agrícolas compatibles con el tránsito ganadero, y las más novedosas que tienen que ver con el esparcimiento o el recreo y con la protección medioambiental, han puesto de relieve algo que propio el Tribunal Constitucional reconoció en su STS 227/1988 relativa a la constitucionalidad de la Ley de Aguas: que al margen del uso o servicio público que justifica primigeniamente una declaración de demanialidad pública existen "otros fines constitucionales legítimos, vinculados en última instancia a la satisfacción de necesidades colectivas primarias, como, por ejemplo, la que garantiza el artículo 45 de la Constitución, o bien a la defensa y utilización racional de la riqueza del país, en cuanto que subordinada al interés general", que subyacen a dicha declaración de demanialidad y también pueden, por tanto, justificarla (F.J. $14^{\circ}$ ).

7 Sobre el reparto de competencias en la materia y la descentralización operada por la Ley 3/1995, de 23 de marzo (que va más allá de las previsiones constitucionales y estatutarias) véase: HERRÁIZ SERRANO, O., op. cit., pp. 102 y ss; ALENZA GARCÍA, J.F., op. cit., pp. 280 y ss; BENSUSAN MARTÍN, Maํ p., "Las vías pecuarias en Andalucía", número extraordinario de esta Revista 2/2003 publicado con ocasión del vigésimo aniversario del Estatuto de Autonomía de Andalucía, volumen I, pp. 385 y ss; así como nuestro citado trabajo sobre las "Vías pecuarias", pp. 554 y ss.

${ }^{8}$ Así lo han destacado HERRÁIZ SERRANO, O., op. cit., pp. 143 y ss., y ALENZA GARCÍA, J.F., op. cit., pp. 324 y ss.
} 
nomas como titulares del dominio público cañadiego "deberá estar orientada hacia la preservación y adecuación de la red viaria, así como a garantizar el uso público de las mismas", lo que es luego refrendado por el art. 3 de la LVP al establecer los fines y los objetivos que han de perseguir las Comunidades Autónomas sobre las vías pecuarias ubicadas en su territorio. Los principios rectores enunciados (preservación, adecuación y garantía de uso público) se configuran, pues, como tres vectores que enmarcan y fundamentan las diversas potestades y prerrogativas que toman cuerpo en la intervención administrativa en esta materia.

Así, en primer término, la finalidad de preservación justifica la aplicación de la clásica serie de potestades de policía demanial, de orientación conservacionista, mediante las que se garantiza la defensa y protección de la titularidad pública y la incolumidad posesoria (que analizaremos en el punto II de este trabajo). En segundo lugar, la finalidad de adecuación aporta una perspectiva funcional y territorial que atiende a la idoneidad y suficiencia del demanio cañadiego, a la operatividad o funcionalidad permanente de las vías pecuarias ${ }^{9}$. Esta pretensión de racionalizar la constitución y la gestión de los bienes demaniales en general, y de las vías pecuarias en particular, da sentido a las potestades administrativas que permiten alterar o hacer desaparecer la afectación de la vía, modificar su trazado o ampliar y restablecer la red cañadiega (en los términos que desarrollaremos en el punto III). En tercer lugar, la finalidad de garantía del uso público configura una serie de potestades y deberes orientados a la preservación del uso público asignado a las vías y a controlar las desviaciones, tanto con carácter preventivo como represivo (punto IV). Finalmente, las vías pecuarias pueden recibir eventualmente una protección adicional a la de su propia normativa por otras disposiciones relativas a la ordenación del territorio y al urbanismo, a la protección ambiental o la protección de los bienes de interés cultural, lo que justifica la exposición de las potestades administrativas contempladas como medidas adicionales de protección por la legislación sectorial que incide en la materia (como veremos en el punto V).

\footnotetext{
${ }^{9}$ Nótese que la idoneidad y la suficiencia son dos de los nuevos principios inspiradores de la gestión de los bienes demaniales que recoge expresamente el artículo 6.b de la Ley 33/2003, de 3 de noviembre, de Patrimonio de las Administraciones Públicas
} 


\section{POTESTADES DE POLICÍA DEMANIAL DIRIGIDAS A LA PRESERVA- CIÓN DE LA TITULARIDAD Y POSESIÓN PÚBLICA DE LAS VÍAS PE- CUARIAS}

Tradicionalmente, la legislación demanial ha contemplado un conjunto de potestades tendentes a la identificación y declaración de la posesión pública de los bienes integrantes del dominio público (fundamentalmente, la investigación y el deslinde), así como a la reivindicación de la posesión perdida o amenazada (recuperación de oficio y desahucio). Todas estas potestades son aplicables a la protección demanial de las vías pecuarias, pese a que no todas están expresamente reconocidas en la legislación de vías pecuarias (el art. 5 de la LVP sólo cita las potestades declarativas de investigación, clasificación, deslinde y amojonamiento). No obstante, ha de tenerse en cuenta que la legislación de vías pecuarias es especial respecto de la legislación general de la materia que actualmente contiene la Ley 33/2003, de 3 de noviembre, del Patrimonio de las Administraciones Públicas (en adelante LPAP), que regula las potestades ejecutorias o reivindicativas no contempladas expresamente por la LVP (la recuperación de oficio y el desahucio) y, en general, aporta importantes novedades respecto a la legislación general de patrimonio anteriormente vigente, en el sentido de reforzar las facultades y prerrogativas de defensa demanial ${ }^{10}$. Asimismo, debe señalarse que la normativa andaluza sobre vías pecuarias, contenida en el Decreto 155/1998, de 21 de julio, por el que se aprueba el Reglamento de vías pecuarias de la Comunidad Autónoma de Andalucía (en adelante, RAVP), establece previsiones específicas que abundan en el régimen de estas potestades y regula íntegramente, además, la recuperación de oficio (arts. 8.f y 27 a 30), que es una potestad que la LVP omite.

\footnotetext{
${ }^{10}$ Véase, en este sentido, mi trabajo sobre las "Facultades y prerrogativas para la defensa de los patrimonios públicos", en los Comentarios a la Ley 33/2003, del Patrimonio de las Administraciones Pú blicas, dirigidos por CHINCHILLA MARÍN, C., Thomson-Civitas, Madrid, 2004, pp. 323 a 369. Por vía de síntesis, puede decirse que la LPAP ha enriquecido la puesta en práctica de las potestades de defensa demanial favoreciendo la autotutela administrativa declarativa y ejecutoria, aparte de prever la aplicación medidas cautelares generalizadas en el ejercicio de todas la potestades (frente a la legislación de vías pecuarias que sólo las prevé ocasionalmente), de sentar el deber general de colaboración ciudadana (fortaleciendo al tiempo la potestad inspectora), o de establecer la obligación notarial de notificar determinados actos y contratos que afecten a bienes y derechos públicos, así como la prohibición de inscripción registral en caso de incumplimiento de esta obligación.
} 


\section{Potestades declarativas} A) Investigación: una potestad venida a menos en la órbita del demanio caña-
diego

En relación a la potestad de investigación, el art. 5.a) de la LVP se limita a enunciar "el derecho y el deber" que tienen las CCAA en orden a "investigar la situación de los terrenos que se presuman pertenecientes a las vías pecuarias", previsión que es reiterada por el art. 8.1.b) del RAVP sin añadir nada sobre los presupuestos o el régimen de ejercicio de esta potestad. Por su parte, el art. 45 de la LPAP (que tiene carácter básico) establece que "las Administraciones públicas tienen la facultad de investigar la situación de los bienes y derechos que presumiblemente formen parte de su patrimonio, a fin de determinar la titularidad de los mismos cuando ésta no les conste de modo cierto".

La potestad de investigación se configura así, más que como una potestad genérica que pueda proyectarse sobre cualquier bien de titularidad indeterminada, como una potestad de ámbito más restringido que deriva siempre de una presunción de dominio. En efecto, como se desprende de los preceptos transcritos, el presupuesto para el ejercicio de la potestad de investigación es la indeterminación de la titularidad del bien, de la que se requieren dos condiciones: que existan indicios de su pertenencia pública y que no haya datos o documentos públicos que puedan acreditarla. Es decir, la investigación está siempre presidida por una confusión o incertidumbre de títulos de propiedad, con independencia que haya o no confusión de los límites de dicha propiedad y de su estado posesorio (aunque el ejercicio de la potestad investigadora sólo parece tener sentido cuando la Administración no tiene la posesión), pues con su ejercicio se persigue exclusivamente averiguar si la titularidad pública del bien, en principio indiciaria, se corresponde con la realidad jurídica.

Pese a su alto potencial jurídico (tiene naturaleza declarativa de la propiedad de los bienes públicos calificados como tales ministerio legis, permitiendo su inscripción -art. 47.d LPAP y art. 53 RBCL- y el inicio de todas las acciones pertinentes para recuperar la posesión) es una potestad en desuso, probablemente por haber nacido al socaire de la política desamortizadora de enajenación de bienes en "manos muertas", escondidos o de titularidad incierta, y con una finalidad ligada a paliar la Deuda que queda patente en su regulación histórica ${ }^{11}$.

\footnotetext{
${ }^{11}$ En desarrollo de la Ley de bienes mostrencos de 9 de mayo de 1835, el Real Decreto de 10 de abril de 1852 reguló la facultad de investigación y estableció la obligación de poner en conocimiento de los fiscales la existencia de bienes vacantes o sin dueño conocido, gratificando con
} 
Su virtualidad en relación a las vías pecuarias es menor en la actualidad, incluso si se piensa que pudiera emplearse esta potestad para averiguar la situación jurídica de determinados terrenos o elementos que pudieran ser parte de una vía pecuaria, es decir, cuando existe incertidumbre no ya sobre la titularidad sino sobre la extensión de la vía; pues, en todo caso, la función formalmente declarativa de la existencia de la vía, incluida la determinación de sus características generales (extensión, anchura y trazado) es el contenido propio de la potestad de clasificación, que absorbe en gran medida la función que la potestad investigadora pudiera desempeñar en este campo. Acaso la principal virtualidad de la investigación pudiera estar en la utilidad auxiliar que la potestad de inspección y el deber de colaboración que acompañan el ejercicio de la acción investigadora (en virtud de lo dispuesto en el art. 62 de la LPAP) pudieran prestar a la hora de determinar la existencia y características generales de la vía y de sus elementos accesorios (majadas, descansaderos, abrevaderos, etc., que, según dispone el art. 4.3 de la LVP habrán de constar en la clasificación).

un tercio de su valor a los particulares que investigasen su situación jurídica. Con este precedente, la Ley desamortizadora de 11 de julio de 1856 (que reformaba la Ley Madoz de 1 de mayo de 1855) reguló la potestad de investigación con carácter general, asignando al Ministerio de Hacienda la tarea de disponer reglamentariamente todo lo necesario para la investigación de los bienes vendibles. Anteriormente, la Instrucción de 31 de mayo de 1855, dictada en desarrollo de la Ley Madoz con objeto de fijar las atribuciones de los distintos órganos de Hacienda en la administración y enajenación de los bienes desamortizados, había designado a la Dirección General de Ventas de Bienes Inmuebles (creada por Real Decreto de 15 de mayo de 1855) como "autoridad superior gubernativa” en todos los negocios de bienes, confiriéndole la específica potestad de promover "la investigación de las fincas, censos, foros y demás propiedades que se hayan ocultado para que sin más demora que la indispensable se incaute de ellas el Estado" (art. 6). En el ámbito de estas disposiciones, correspondía a los Gobernadores civiles promover las investigaciones en cada Provincia. Éstos, a su vez, designarían a los "comisionados" encargados de descubrir en cada distrito las propiedades ocultas o ignoradas a cambio de un porcentaje sobre el valor de venta. Posteriormente, la Real Orden de 8 de junio de 1896 reguló un sencillo procedimiento de investigación, cuya competencia se atribuyó a las Delegaciones Provinciales de Hacienda (creadas por la Ley de 9 de diciembre de 1881). Poco más tarde, con la aprobación del Reglamento de Inspección de bienes de 15 de abril de 1902, el procedimiento de investigación queda definido en todos sus perfiles. Si bien, el Real Decreto de 11 de enero de 1908 reformó el ámbito de la potestad investigadora para constreñirla tan sólo a los bienes cuyo descubrimiento pudiera ser de alguna utilidad para el Tesoro público. Cabe consignar, por lo demás, que la potestad investigadora, entendida desde su origen como un acto de concreción de alcance declarativo de una titularidad pública predeterminada en la legislación desamortizadora, se acompaña, en origen, de la potestad reivindicatoria para "incautar" el bien a su poseedor ilegítimo, en un momento histórico en el que la potestad de recuperación de oficio no estaba aún formalmente reconocida. 
B) La clasificación de vías pecuarias como acto singular de afectación demanial: consecuencias jurídicas

La clasificación es una potestad muy singlar que tiene su razón de ser en el carácter artificial y la historia de auge y declive de estas vías. El sentido histórico de la potestad de clasificación de las vías pecuarias está íntimamente unido al peculiar proceso de desamortización que sufrieron estos caminos a partir el Real Decreto-Ley de 1924. La clasificación se configuraba en dicha disposición -la primera en regular esta potestad- como un acto de determinación de la necesidad o innecesariedad de la vía con vistas a su enajenación, para lo que era necesario levantar acta previa de su existencia y realidad física.

Toda vez que la legislación vigente ha desterrado la finalidad desamortizadora que en mayor o menor medida caracterizó a la legislación anterior, la clasificación concibe en la LVP como un procedimiento administrativo de carácter declarativo en cuya virtud se determina la existencia, anchura, trazado y demás características físicas generales de cada vía pecuaria (art. 7). También corresponde al acto de clasificación la determinación de la superficie de los elementos asociados a las vías (abrevaderos, descansaderos, majadas y demás lugares asociados al tránsito ganadero), así como la determinación de la anchura de las coladas (art. 4.3). Parece así que la lógica de la potestad de clasificación responde a la necesidad de determinar sobre el terreno la existencia de cada vía, en tanto que éstas no se definen en la Ley por remisión a una realidad natural, lo que justifica que el ejercicio de esta potestad sea una pieza necesaria y preceptiva para la puesta en práctica del régimen legal de protección (hasta el punto de que la Disposición Adicional Primera de la LVP prevea la urgente clasificación de las vías pecuarias no clasificadas con anterioridad).

En relación a la naturaleza jurídica de esta potestad, la jurisprudencia tiene declarado que la clasificación no tiene efectos jurídicos constitutivos de la posesión o de la titularidad, para lo que se requiere el ulterior deslinde ${ }^{12}$. La clasificación se ciñe, pues, a determinar la existencia de la vía fijando sus características físicas generales al objeto de su posible identificación en el acto de deslinde (art. 15.3 RAVP), que ya se ocupará de precisar las características

\footnotetext{
12 Vid., por todas, la STS de 27 de abril de 1999 (Ar. 3327), con cita de la jurisprudencia anterior.
} 
concretas de la vía. La importancia de este acto reside, por tanto, en la determinación de la existencia de la vía, de modo que su contenido jurídico declarativo no es sino la concreción de la afectación legal genérica.

Esta afectación singular de la vía a la categoría de bien demanial que consagra el acto de clasificación constituye una declaración jurídica de la máxima importancia. La razón es -como antes apuntábamos- que las vías pecuarias (a diferencia de otras declaraciones demaniales) no son bienes de dominio público "naturales" o "por naturaleza" 13 cuya condición demanial quede definida por remisión del legislador a una realidad necesariamente identificable y reconocible. Antes bien, las vías pecuarias pertenecen al llamado dominio público "artificial" porque, de un lado, son producto de la actividad humana o necesitan de ésta para existir y, de otro, porque la declaración legal de demanialidad no basta por sí sola para afectar estos bienes a un uso público, sino que tal declaración ha de ser completada a posteriori por el acto de afectación concreto en que consiste la clasificación. Con lo cual, hasta que no se haya clasificado la vía no serán de aplicación las prerrogativas de protección demanial ni las notas típicas del demanio y, en consecuencia, hasta ese momento quedarían a salvo los derechos de propiedad, sin que pueda considerarse que tales derechos, siempre que se hayan consolidado con anterioridad al acto de clasificación, se extinguen por la misma.

A pesar de su importancia declarativa, la LVP no regula el procedimiento de clasificación, limitándose a señalar que los actos de clasificación acordados por las Comunidades Autónomas que afecten a vías pecuarias integradas en la Red nacional se incorporarán al Fondo Documental de Vías pecuarias de la Administración del Estado (art. 18.5). En desarrollo de las escasas previsiones de la LVP, la legislación autonómica concibe la clasificación como una potestad dirigida a la fijación de las características físicas y morfológicas de las vías pecuarias con vistas a determinar su eje y trazado (y, en su caso, los elementos sobrantes de cada vía), que se orienta a declarar la existencia e identificación de una vía pecuaria con objeto de proceder a su posterior deslinde,

\footnotetext{
${ }^{13}$ Pese a que algunos autores afirmen tal condición, como hace GONZÁLEZ GARCÍA, J.V., La titularidad de los bienes de dominio público, Marcial Pons, Madrid, 1998, p. 201 y ss.; o, de forma más matizada, DARNACULLETA i GARDELLA, M., Recursos naturales y dominio público: el nuevo régimen del demanio natural, Cedecs, Barcelona, 2000, p. 193. Cosa que es contradicha por ALENZA GARCÍA, op. cit., pp. 321 y ss. o PONCE SOLÉ, J., Régimen jurídico de los caminos y Derecho de acceso al medio natural, Marcial Pons, Madrid-Barcelona, 2003, p. 45; y HERRÁIZ SERRANO, O., op. cit., pp. 304 y ss.
} 
del que la clasificación tiene carácter preparatorio; por lo que puede decirse que clasificación y deslinde se configuran como piezas separadas un procedimiento integrado en el que el deslinde sería el acto ejecutivo de la clasificación ${ }^{14}$.

La clasificación de las vías pecuarias se tramita mediante un expediente autonómico al que han de servir como fundamento cuantos antecedentes existan en el Fondo Documental de vías pecuarias, en los Ayuntamientos afectados y en cualquier otro organismo ${ }^{15}$. Junto a ello, la legislación autonómica prevé que, una vez emitido el acuerdo de clasificación se proceda al reconocimiento y recorrido de la vía pecuaria con los representantes y prácticos del lugar designados, al objeto de redactar la propuesta de clasificación, que determinará la dirección, anchura y longitud aproximada de la vía junto a la descripción detallada de su itinerario, linderos, superficie aproximada y características de los descansaderos, majadas y abrevaderos; determinándose asimismo los terrenos sobrantes e innecesarios.

En el ámbito de la Comunidad Autónoma andaluza, el procedimiento de clasificación se regula de forma prolija en los arts. 12 a 16 del RAVP, que establecen ciertas garantías de publicidad (arts. 14.2 y 16.1), de participación ciudadana (art. 15) y que someten al acto de clasificación al régimen de los recursos administrativos del la LRJAP y PAC (art. 16.2). Con todo, y a pesar de la expresa referencia que hace el art. 14.2 del RAVP a la notificación personal a los interesados en el plazo de diez días desde la publicación del anuncio de las operaciones materiales de clasificación que han de hacerse sobre el terreno, no debe obviarse lo frecuente que en la práctica resulta que los interesados desconozcan la existencia de la clasificación, ya que la inmensa mayoría de las clasificaciones sobre las que operan los actuales deslindes fueron efectuadas por la Administración en los años 50 y 60 (sobre todo a partir de la aprobación del Reglamento de 1944), cuando la normativa entonces vigente no establecía la exigencia de notificación administrativa ni las garantías procedimentales que hoy establece el RAVP.

\footnotetext{
${ }^{14}$ HERRÁIZ SERRANO, O., op. cit., p. 439 y 454 y ss.

${ }^{15}$ En este sentido hay que recordar que la LVP prevé la existencia de un Fondo Documental de Vías Pecuarias en el Ministerio de Agricultura, Pesca y Alimentación, donde se recogen la clasificación y demás actos que afecten a las vías pecuarias integradas en la Red Nacional de Vías Pecuarias (art. 18.5 Ley de Vías Pecuarias). Las Comunidades Autónomas han previsto sus propios Fondos Documentales para el mejor conocimiento y gestión de las vías pecuarias que discurren por su territorio.
} 
Surge así la pregunta, de la mayor relevancia práctica, de si el particular que solo tiene conocimiento del acto de clasificación en el momento del deslinde (normalmente muy posterior) puede, entonces, impugnar aquella clasificación, lo que debe responderse en función de la naturaleza jurídica de dicho acto de clasificación. En este sentido, dado que la clasificación no es constitutiva ni declarativa de posesión o de la propiedad, sino tan solo de la existencia de la vía, difícilmente podrá argüirse el desconocimiento de derechos preexistentes por el acto de clasificación que, en puridad, no puede comportar por sí mismo privación de derechos patrimoniales. De ahí que, transcurrido el plazo ordinario de recurso frente al acto de clasificación, tal resolución devenga firme y, en consecuencia, la vía pecuaria -todavía no concretada sobre el terreno hasta su deslinde- gozará desde entonces de la condición de dominio público, por lo que no podrá después impugnarse su deslinde invocando únicamente razones que tiendan a demostrar que no concurría el presupuesto necesario para la clasificación de los terrenos como vía pecuaria ${ }^{16}$. Aunque ello no impediría, sin embargo, la eventual interposición de un recurso extraordinario de revisión, si se dan los presupuestos de las reglas $1^{\underline{a}}$ o $2^{2}$ del art. 118.1 de la LRJAP y PAC, o su revisión en virtud de los arts. 102 ó 103 de dicha Ley. O acaso, más allá de los motivos de legalidad en los que se sustentan las mencionadas vías revisorias, también debe considerarse la posibilidad de que pueda prosperar una pretensión de revisión de la clasificación basada en motivos de oportunidad que concluyesen con la eventual desclasificación (desafectación) de la vía o la modificación de su trazado, o en la im-

\footnotetext{
16 Tal es la conclusión a la que llega una importante Sentencia del Tribunal Superior de Justicia de Andalucía, de 22 de diciembre de 2003 (rec. núm. 2101/1998) que luego comentaremos más detenidamente. Según este pronunciamiento, "no es condición de validez del expediente administrativo de clasificación la investigación sobre la identidad de los colindantes y de los poseedores con o sin título de los terrenos por los que in genere ha de transcurrir la vía pecuaria, ni por lo tanto tampoco la notificación personal a cada uno de ellos, del mismo modo que tampoco se exige como condición de validez dicha notificación personal -sino publicidad en diarios oficiales y trámite de información pública- para otros actos administrativos que pueden afectar a situaciones jurídico-privadas, como son la clasificación de espacios naturales, el planeamiento urbanístico, etc. La razón es bien simple: como antes se ha razonado, el acto de clasificación no comporta por sí solo en ningún caso privación, perjuicio o expropiación automática de titularidades jurídico-privadas consolidadas con anterioridad, las cuales podrán hacerse valer en el momento en que se proceda al deslinde y, ahora sí, con notificación personal suficiente, se concrete sobre el terreno, metro cuadrado por metro cuadrado, el trazado de la vía pecuaria. Pero el interés diferenciado del poseedor o pretendido dueño de terrenos afectados se agota en la defensa de su posesión o propiedad, sin que goce por esa circunstancia de especiales posibilidades o garantías para la eventual impugnación del acto de clasificación". A la misma conclusión llegan, con parecido razonamiento, sendas sentencias del Tribunal Superior de Justicia de Extremadura de 14 de julio de 2005 (rec. núms. 794/2003 y 804/2003).
} 
posición de alguna medida más respetuosa con los derechos preexistentes como sería la del establecimiento de una servidumbre administrativa, que son técnicas en las que luego abundaremos.

\section{C) Deslinde y amojonamiento de vías pecuarias. El problema de los derechos de propiedad privada preexistentes}

Entre las potestades administrativas que la LVP ha regulado en orden a la conservación y defensa de las vías pecuarias destaca la incisiva regulación del deslinde (art. 8), que merece especial consideración por nuestra parte. El deslinde aparece contemplado en la regulación de las vías pecuarias desde mediados del s. XIX ${ }^{17}$, donde la potestad era configurada de acuerdo con sus perfiles clásicos; esto es, como la facultad de fijar los límites físicos concretos de las vías pecuarias respecto de las fincas colindantes mediante la práctica de operaciones técnicas de comprobación o, en su caso, de rectificación de situaciones jurídicas acreditadas, que tenían por objeto delimitar los linderos de las vías y a declarar la posesión de las mismas. En origen, por tanto, el deslinde no tiene como finalidad necesaria -a diferencia de la acción reivindicatoriasolventar una controversia posesoria (aunque tiene efectos posesorios declarativos), siendo su finalidad típica la de constatar la identificación de unos bienes que se encuentran en una situación de colindancia imprecisa, al objeto de comprobar la armonía del título de propiedad con la realidad y con independencia de las situaciones de usurpación o perturbación posesoria ${ }^{18}$.

De la regulación anterior del deslinde de vías pecuarias, que respondía a la caracterización tradicional de esta potestad, se deducía claramente que la naturaleza del deslinde no era declarativa de propiedad, ciñendo sus efectos

\footnotetext{
${ }^{17}$ La regulación originaria del deslinde administrativo de vías pecuarias estaba contenida en el primer Reglamento de organización y régimen de la Asociación de Ganaderos de 31 de marzo de 1854 -aunque regulado de forma imprecisa, confundido con una genérica potestad de conservación y defensa de las servidumbres pecuarias-, de donde pasa al posterior Real Decreto de 3 de marzo de 1877, que sí contiene una detallada y autónoma regulación de la figura. Como ha puesto de manifiesto la doctrina, la confusión entre las potestades de deslinde administrativo y recuperación es notable en este momento histórico, en tanto que el deslinde va acompañado de una autoreivindicación demanial del ius possidendi que la Administración ostenta sobre los bienes deslindados, lógica consecuencia de la incardinación de estas prerrogativas en la más genérica potestad recuperatoria derivada de la policía de conservación de la Administración sobre sus bienes. Sobre el alcance y efectos de la potestad de deslinde desde su concepción originaria, véase, por todos, RIVERO YSERN, E., El deslinde administrativo, Instituto García Oviedo, Sevilla, 1967, pp. 38 y ss.

${ }^{18}$ Siguiendo esta concepción clásica del deslinde, la legislación condiciona el ejercicio de dicha potestad a un doble presupuesto de hecho: que los límites entre propiedades a deslindar "sean imprecisos o existan indicios de usurpación" (art 50.1 LPAP y 56.1 RBCL). No se trata, pese a
} 
al estricto ámbito posesorio. Así, la jurisprudencia señaló en numerosas ocasiones que la potestad de deslinde no supone una acción reivindicatoria y que, desde luego, no es título suficiente para sustentar el derecho de propiedad ${ }^{19}$. El deslinde declara simplemente la posesión de lo deslindado (así lo dice expresamente el art. 57.2 del RBCL), pero ni siquiera es un título de posesión pleno, pues no destruye la presunción posesoria que se deriva a favor del titular registral. En este sentido, cabe recordar que la Ley Hipotecaria (LH) dispone que, a todos los efectos, se presumirá que los derechos reales inscritos en el Registro de la propiedad existen y pertenecen a su titular en la forma determinada por el asiento respectivo, añadiendo que el que tenga inscrito el dominio de inmuebles o derechos reales sobre los mismos tiene su posesión, no pudiendo ejercitarse ninguna acción contradictoria del dominio o de derechos reales inscritos a nombre de persona o entidad determinada sin que, previamente o a la vez, se entable demanda civil de nulidad o cancelación regis-

lo que pudiera desprenderse de la literalidad de la expresión legal, de un requisito alternativo, ya que la jurisprudencia ha declarado reiteradamente que la confusión de linderos es un presupuesto inexcusable para el ejercicio de la acción de deslinde (ya sea esta civil o administrativa), con independencia de que haya o no indicios de usurpación. Así, el deslinde no es viable "cuando los inmuebles se encuentran perfectamente identificados y delimitados, con la consiguiente eliminación de la incertidumbre respecto de la aparente extensión superficial del fundo y a la manifestación del estado posesorio" (STS de 18 de abril de 1984 -Ar. 1959-). Por su parte, las STS de 3 de noviembre de 1989 (Ar. 7844), declara que "para proceder al deslinde de inmuebles es requisito imprescindible que los límites estén confundidos, de manera que no se tenga conocimiento exacto de la línea perimetral de cada propiedad". Pues, como afirmaba la Sala Primera del Supremo en su antigua sentencia de 13 de mayo de 1959, "la acción de deslinde es semejante a la antigua finium regundorum, con la que mantiene puntos notorios de semejanza y, aunque no pueda con ella identificarse, requiere como supuestos fundamentales el dominio de las fincas cuyo deslinde se pretende y la confusión de linderos con otra del demandado y cuya propiedad pertenece a este". Por otro lado, la consideración que hace la legislación la existencia de "indicios de usurpación" como presupuesto del deslinde administrativo, provoca una cierta asimilación entre los presupuestos legitimadores del ejercicio de esta potestad y los de la recuperación de oficio. Ello obliga a delimitar qué haya de entenderse por "indicios de usurpación" a los efectos de estimar procedente la acción de deslinde o la de recuperación de oficio, cuyo ejercicio reclama la consumación de la usurpación, es decir, que la posesión se haya perdido indebidamente (como expresa el art. 55.1 de la LPAP).

${ }^{19}$ En palabras de la STS de 3 de marzo de 1992 (Ar. 1775), "el deslinde no puede convertirse en una acción reivindicatoria simulada, y no puede con tal pretexto la Administración hacer declaraciones de propiedad sobre terrenos en los que los particulares ostenten derechos de propiedad y prueben una posesión superior a un año, ya que el deslinde sólo sirve para la fijación precisa de la situación posesoria entre las fincas deslindadas". Véanse, en parecido sentido, las SSTS de 26 de enero de de 1984 (Ar. 159), de 22 de mayo de 1985 (Ar. 2935), de 17 de junio de 1987 (Ar. 4550), de 3 de marzo de 1994 (Ar. 2416), de 7 de febrero de 1996 (Ar. 985) o la más reciente STS de 27 de mayo de 2003 (Ar. 4104). 
tral (art. $38 \mathrm{LH})$. Inatacabilidad de los derechos inscritos que corroboran los arts. 32 y 34 de la LH al fijar los efectos de la fe pública registral y los arts.1 y 40 al disponer que los asientos practicados en los libros de Registro están bajo la salvaguarda de los Tribunales y producirán sus efectos mientras no se declare su inexactitud en los términos establecidos en la propia LH.

La gran novedad de la vigente LVP es haberle otorgado al deslinde unos efectos hasta ahora desconocidos en la órbita del dominio público cañadiego, a fin de dispensar a éste la máxima protección. En este sentido, ha tenerse presente que, con anterioridad, la legislación sectorial en materia de costas (art. 13 de la Ley 22/1988, de 28 de julio) y de aguas (en los términos que actualmente recoge el art. 95 del Texto Refundido de 20 de julio de 2001), dotaron al deslinde de efectos declarativos de la posesión y de la titularidad demanial, a la vez que conferían a dicho título eficacia prevalente respecto a las titularidades registrales contradictorias, lo que elevaba el alcance y efectos de esta potestad mucho más allá de los limitados y provisionales efectos declarativos de la posesión que le confiere la legislación general sobre patrimonios públicos. Pues bien, la legislación de vías pecuarias equipara la naturaleza y efectos del deslinde a lo prevenido en la legislación de costas y de aguas, afirmando que el acto resolutorio del deslinde declara la posesión y la titularidad demanial a favor de la Comunidad Autónoma, sin que las inscripciones preexistentes del Registro de la Propiedad puedan prevalecer frente a la naturaleza demanial de las vías deslindadas, ya que la aprobación del deslinde es título suficiente para rectificar las situaciones jurídicas registrales contradictorias con el mismo y, en caso de terrenos que nunca accedieron al Registro, para inmatricular el bien a favor de la Comunidad Autónoma (art. 8.3 y 4 Ley y 23.2 RAVP). Todo ello sin perjuicio de las acciones civiles de los afectados, cuya situación posesoria y reivindicativa pueden anotarse marginalmente y preventivamente en la inscripción del deslinde (art. 8.4 y 5 de la LVP) ${ }^{20}$.

De este modo, la vigente LVP ha reforzado las notas de la imprescriptibilidad e inalienabilidad del dominio público cañadiego para poner fin a la orientación legislativa anterior que, en mayor o menor medida, venía reconociendo efectos a las posesiones legitimadas por el transcurso del tiempo y, en general, a los derechos de propiedad consolidados ${ }^{21}$. Esta extralimitada con-

\footnotetext{
${ }^{20}$ En este punto es obligada la remisión al estudio de HORGUÉ BAENA sobre las consecuencias jurídicas que tiene esta nueva consideración del deslinde, El deslinde de costas, Tecnos, Madrid, 1995, pp. 311 ys.
} 
figuración del deslinde, que difiere mucho de su tradicional alcance, sitúa a la Administración en una posición impropia que no sólo se aparta de la regulación de esta figura en la LPAP y en el RBCL sino que, a nuestro juicio, supone también una falla importante para el sistema registral inmobiliario y para la tradicional concepción de la dualidad jurisdiccional que informa la competencia de los Tribunales para conocer las actuaciones administrativas dirigidas a la defensa de los patrimonios públicos (que actualmente plasma el art. 43 de la LPAP), en la medida que consagra la ruptura del monopolio del juez civil para conocer de cualquier cuestión relativa al dominio, aun cuando éste fuera de titularidad pública, atribuyendo a la Administración autonómica que promueve el deslinde la facultad de decidir -en vía administrativa- sobre la posesión y la titularidad dominical a su favor, dando lugar al consiguiente amojonamiento, y sin que las inscripciones registrales puedan prevalecer frente a la naturaleza demanial de los bienes deslindados, hasta el punto de que la realidad extraregistral del deslinde administrativo goza del valor de enervar la presunción iuris tantum que confiere el Registro de la Propiedad a las titularidades inscritas.

No obstante, pese al incisivo alcance del deslinde, debe subrayarse que los efectos declarativos de la propiedad y la posesión administrativa del deslinde de vías pecuarias se producen sin perjuicio de que los titulares inscritos puedan hacer valer sus derechos ante la jurisdicción civil, tal y como reconoce el propio art. 8 de la LVP (apdos. 4 in fine y 6 ) y como ha declarado la jurisprudencia en relación al deslinde de $\operatorname{costas}^{22}$. En efecto, aunque a partir de la

\footnotetext{
${ }^{21}$ La legislación anterior sobre vías pecuarias, aparte de limitar los efectos del deslinde a la declaración posesoria a favor de la Administración, dejó siempre una puesta abierta al reconocimiento de la usucapión y de otros títulos de propiedad. Así, el art. 1 del Real Decreto-Ley de 5 de junio de 1924, tras decir que "las vías pecuarias son bienes de dominio público" que "no serán susceptibles de prescripción y no podrá alegarse para su apropiación el mayor o menor tiempo que hubieran sido ocupadas, ni en ningún caso podrán legitimarse las usurpaciones de que sean objeto", excepciona la facultad de restablecimiento y reivindicación de las mismas por parte de la Administración en "los casos en que se haya legitimado, conforme a las Leyes, el derecho adquirido, haciéndose la adquisición irreivindicable”. Parecida redacción se repite en la base $2^{\mathrm{a}}$ del Decreto de 7 de diciembre de 1931 y en el art. 1 del Decreto de 23 de diciembre de 1944, por el que se aprobó el Reglamento de vías pecuarias. Por su parte, el art. 1 de la anterior Ley 22/1974, de 27 de junio, de vías pecuarias, insistió en que "las vías pecuarias (...) no son susceptibles de prescripción ni de enajenación, ni podrá alegarse para su apropiación el tiempo que hayan sido ocupados, ni legitimarse las usurpaciones de que hayan sido objeto". No obstante, el problema de la propiedad privada sobre las vías pecuarias se mantuvo vivo desde el momento en que la Disposición Final primera preveía que "lo dispuesto en esta Ley se entiende sin perjuicio de los derechos legalmente adquiridos que hayan hecho irreivindicables los terrenos ocupados de vías pecuarias, y cuyas situaciones se preciarán por los Tribunales de Justicia”.
} 
aprobación vigente LVP la jurisprudencia no podrá recurrir, como antaño hacía, al plazo treintenal para impedir la reivindicación administrativa de las vías pecuarias ${ }^{23}$, ello no significa necesariamente que la Administración pueda reivindicar cualquier terreno que en el pasado haya tenido tal carácter. $\mathrm{Al}$ admitir la competencia del orden jurisdiccional civil sobre las cuestiones de propiedad en los conflictos de fondo suscitados a raíz del deslinde de las vías pecuarias, se está admitiendo implícitamente que el juez civil pueda reconocer derechos de propiedad a favor de terceros, cosa que creemos que puede suceder en estos tres supuestos, que son los que señala la STSJ de Andalucía de 22 de diciembre de 2003 (rec. núm. 2001/1998):

a) que el terreno hubiese sido enajenado o permutado en el pasado por la Administración (como permitía la legislación anterior, previa clasificación de innecesariedad de la vía);

b) que se hubiese legalmente usucapido conforme a los arts. 1940 y ss. del Código Civil; o

c) que se hubiese producido una adquisición de las prevenidas por el art. 34 de la LH que, más allá de la presunción iuris tantum de exactitud y de posesión sentada por el art. 38 de la LH, reconoce ex lege el derecho inatacable de quien, confiado en la publicidad y seguridad registral, adquiere a título oneroso y de buena fe a quien no es dueño pero figura como tal en el Registro.

\footnotetext{
${ }^{22}$ SSTS de 10 de febrero de 1998 (Ar. 1586), de 31 de marzo de 1998 (Ar. 3940), de 19 de mayo de 1999 (Ar. 4154), de 5 de julio de 2001 (Ar. 5022), y de 24 de septiembre de 2001 (Ar. 7665).

${ }^{23}$ Aunque el Real Decreto de 1892 no establecía un plazo definido para la usucapión de las vías pecuarias en favor de poseedores de buena fe (de ocupaciones "de larga fecha" hablaba su art. 13.2), el posterior Real Decreto-Ley de clasificación y deslinde de las vías pecuarias de 5 de junio de 1924 estableció la prescripción treintenal como límite de la reivindicación de las vías pecuarias por la Administración. Pero la normativa posterior, tras proclamar la imprescriptibilidad de las vías pecuarias, reconoció la existencia de usurpaciones irreivindicables para la Administración sin fijar, de nuevo, un plazo de prescripción. Ante tal circunstancia, la jurisprudencia se remontó a los antecedentes legales y al propio al Código Civil para admitir la prescripción treintenal de las vías pecuarias. Para la jurisprudencia, el dominio público o es absolutamente imprescriptible o no lo es, y como las vías pecuarias no lo son, porque la normativa admitía la legitimación de algunas ocupaciones, el plazo de prescripción debía ser el treintenal del Código Civil (SSTS de 22 de marzo de 1958 -Ar. 1352-, de 4 de mayo de 1959 -Ar. 1888-, de 15 de noviembre de 1962 -Ar. 4454-, de 31 de mayo de 1988 -Ar. 4060-, de 10 de febrero de 1989 -Ar. 998-, o de 22 de marzo de 1990 -Ar. 5426-, entre otras muchas). Sobre esta cuestión véanse PARRA LUCÁN, Ma A., Vías pecuarias y pro piedad privada, Dykinson, Madrid, 2002, en especial, pp. 75 y ss.; y ALENZA GARCÍA, J.F., op. cit., pp. 387 y ss.
} 
A mi juicio, en estos supuestos en los que existe un título adquisitivo que genera una confianza legítima en el ocupante la Administración no podrá alegar la imprescriptibilidad que fundamenta a los efectos declarativos del deslinde, sino que deberá acudir, como certeramente ha apuntado ALENZA GARCÍA, al mecanismo de la expropiación y afectación posterior de la vía ${ }^{24}$ (para lo que la Administración contará ya con la declaración de utilidad pública que le confiere el art. 6 de la LVP a los efectos del "restablecimiento de la vía”); tesis que cuenta con algún respaldo jurisprudencial reciente ${ }^{25}$. En todo caso, la inatacabilidad de los derechos de terceros está condicionada a que la adquisición alegada se hayan producido antes del acto administrativo de clasificación, pues, como vimos, éste acto consagra la afectación de la vía pecuaria y declara el carácter demanial de la misma, que sería así el dies a quo para la aplicación plena del régimen de protección exorbitante y del predicado de las notas de inalienabilidad e imprescriptibilidad ${ }^{26}$.

\footnotetext{
${ }^{24}$ Op. cit., p. 403.

${ }^{25}$ Así, la citada Sentencia del Tribunal Superior de Justicia de Andalucía, de 22 de diciembre de 2003, afirma certeramente que "por exigencias del art. 33 de la Constitución, debe mantenerse intacto el principio de que allí donde se haya producido conforme a la normativa (civil e hipotecaria) vigente en su memento, una adquisición plena y firme del derecho de propiedad (con o sin inscripción registral) sobre terrenos que después vayan a ser deslindados, ese derecho podrá esgrimirse frente a la Administración y será obstáculo para la adquisición plena de los terrenos a favor de la Comunidad Autónoma correspondiente, mientras no se produzca formalmente la ex-
} propiación".

${ }^{26}$ En función de que se haya o no producido la clasificación, la citada Sentencia del Tribunal Superior de Justicia de Andalucía de 22 de diciembre de 2003, diferencia casuísticamente y con toda exactitud los posibles supuestos de reivindicación demanial frente al deslinde por parte de los particulares: "en el caso de la usucapión, si ésta se consumó por posesión continuada de treinta años, en concepto de dueño, pública y pacifica antes de la fecha de la clasificación, está claro que el usucapiente, y sus causahabientes (herederos, donatarios, compradores, etc.) estarán protegidos frente a la posterior clasificación y deslinde, pudiendo hacer prevalecer su derecho"; caso éste al que habría que equiparar, en mi opinión, el supuesto de adquisiciones privadas por enajenación o permuta operadas por la Administración con anterioridad a la clasificación de la vía (bien previa desafectación, bien -justamente- por su clasificación de vía "innecesaria" conforme a la legislación anterior). A lo que la citada sentencia añade que "si la usucapión no se había consumado antes de la clasificación, entonces jugará de pleno la regla de imprescriptibilidad del dominio público, decayendo, sin derecho a indemnización por justiprecio. La única excepción a esta regla la comportaría el caso de desafectación, que permitiría una usucapión posterior a la misma. Pero evidentemente, entonces tendrían que acreditarse los treinta años de posesión posteriores al acto de clasificación, sin que resulten computables los años que se poseyó con anteriori- 
En este orden de consideraciones, la doctrina ha puesto de relieve algunos de los problemas que ocasiona esta exorbitante regulación del deslinde de las vías pecuarias en relación a los derechos de terceros. Así, PARRA LUCÁN ha denunciado que la LVP parece suponer el carácter usurpador de todas las ocupaciones habidas sobre las vías pecuarias, pasando por alto los derechos de posesión y propiedad que pueden tener un origen legítimo y ser dignos de mayor protección. La misma autora advierte la dificultad de comprender la previsión de unos efectos tan exorbitantes para el deslinde de las vías pecuarias habida cuenta que estos bienes no integran, a diferencia de las costas o las aguas, el llamado dominio público natural, ni la Ley las identifica -ni podría hacerlo- por sus características físicas intrínsecas, sino por una circunstancia aleatoria: el hecho de ser o haber sido caminos de trashumancia ${ }^{27}$.

Por su parte, ALENZA GARCÍA ha formulado dos graves reproches al art. 8 de la LVP: el de su innecesariedad y el de su inconstitucionalidad ${ }^{28}$. Según el razonamiento del citado autor, el reforzamiento de la eficacia del deslinde de vías pecuarias es innecesario por dos razones: en primer lugar, porque en este ámbito las inscripciones registrales por sí solas no invalidaban ni paralizaban el deslinde ${ }^{29}$; en segundo lugar, es innecesario otorgar al deslinde esta eficacia porque en las vías pecuarias es la clasificación la que determina su existencia, configurándose el deslinde como un acto subordinado a la clasifi-

dad al mismo". Y lo mismo ocurre con la eficacia de la fe pública registral, ya que, como precisa la citada sentencia "si antes de la fecha de la clasificación algún particular adquirió con todos los requisitos del artículo 34 de la Ley Hipotecaria (es decir, adquirió de quien constaba en el Registro como titular y con facultades para transmitir, a título oneroso, de buena fe, e inscribiendo a su nombre), entonces su adquisición sería mantenida a pesar de la clasificación posterior, gozando también de protección, en consecuencia, sus causahabientes posteriores (herederos, compradores, etc.). Nótese que en este caso ya no está haciéndose prevalecer la $<<$ inscripción $\gg>$ sobre el acto de deslinde, sino el $<<$ derecho adquirido $\gg$, no por la inscripción, sino por el mecanismo de la protección de la fe pública registral establecido en el artículo 34 de la Ley Hipotecaria. Pero si esta misma adquisición con los requisitos de dicho artículo se produce después de la clasificación, ha de prevalecer la protección reforzada de lo que ya tiene consideración de dominio público, sin necesidad alguna de inscripción registral, y sin perjuicio, desde luego, de las eventuales acciones civiles del adquirente contra el trasmitente por evicción".

27 Op. cit., en especial, pp. 174 y ss.

28 Op. cit., pp. 422 y ss.

${ }^{29}$ Según la jurisprudencia, el deslinde sólo debía respetar las inscripciones registrales cuando eran corroboradas por otros documentos y circunstancias que probaran la prescripción de la vía pecuaria o su inexistencia (STS de 10 de junio de 1991 -Ar. 4676-) 
cación, como acto de ejecución complementario de la misma ${ }^{30}$. Para ALENZA, todo ello ha escapado de la inteligencia del legislador, que no ha caído en la cuenta de que es posible que los efectos del deslinde puedan enervarse si las inscripciones registrales se oponen con éxito a la clasificación, de la cual no puede separarse el deslinde. En cuanto a la posible inconstitucionalidad, el citado autor expone que si bien la privación de derechos que se derivaba de la regulación del deslinde de costas era compensada por la propia Ley de costas, al prever la transformación de esos derechos en concesiones administrativas sobre el dominio público marítimo-terrestre, la traslación de la eficacia del deslinde de costas a las vías pecuarias no ha sido acompañada de compensación alguna por la privación de derechos que impliquen los nuevos deslindes. En este último orden de consideraciones, MARTÍN REBOLLO ha propuesto una interpretación conciliadora para salvar la constitucionalidad de la LVP: que la eficacia del nuevo deslinde sólo pueda operar respecto inscripciones registrales posteriores a la vigencia de la Ley de Vías Pecuarias ${ }^{31}$.

Por otra parte, debe recordarse la dualidad jurisprudencial que rige esta materia (art. 8.6 LVP y 43 LPAP), que limita el conocimiento de la jurisdicción contencioso-administrativa a la existencia de vicios formales de competencia o procedimiento $^{32}$ (a los que habría que asimilar los supuestos de contradicción

\footnotetext{
${ }^{30}$ Por ello el deslinde de vías pecuarias siempre ha tenido una eficacia más limitada que el practicado sobre otros bienes de dominio público, ya que no puede alterar lo dispuesto en la clasificación, como declaran las SSTS de 23 de mayo de 1979 (Ar. 2527) y de 12 de abril de 1985 (Ar. 3519).

31 "Régimen jurídico de los caminos", en el libro homenaje al Prof. MARIENHOFF, Derecho Ad ministrativo, Abeledo-Perrot, Buenos Aires, 1998, p. 1135.

${ }^{32} \mathrm{El}$ art. 43 de la LPAP regula el control judicial de los actos administrativos dictados en los procedimientos que se sigan para el ejercicio de las facultades de defensa patrimonial. El precepto no innova el régimen vigente ni la regulación precedente. Siguiendo las previsiones ya contenidas en art. 8.2 de la LPE, así como en el art. 101 de la LRJPAC, comienza declarando la inviabilidad de la acción interdictal para la tutela sumaria de la posesión prevista en el artículo 250.4..$^{\circ}$ de la LEC frente a las actuaciones administrativas de ejecución de las potestades de autotutela de los bienes públicos. Junto a ello, los arts. 41.2 y 43.2 de la LPAP recogen la tradicional dualidad jurisdiccional según la cual tales actos y actuaciones sólo podrán ser recurridos ante la jurisdicción contencioso-administrativa por infracción de las normas sobre competencia y procedimiento, previo agotamiento de la vía administrativa, y sin perjuicio del ejercicio por quienes se consideren perjudicados por dichos actos, en cuanto a su derecho de propiedad u otros de naturaleza civil, de las acciones pertinentes ante la jurisdicción civil, en el entendido de que en estos casos habrá de interponerse la previa reclamación en vía administrativa (tal y como recoge el art. 41.1.b de la LPAP en conexión con prevenido por el art. 43.2 in fine de la propia LPAP). La previsión supone un especie de reedición de la doctrina de los "actos separables" en la medida que sienta la competen-
} 
entre el acto de deslinde y la clasificación -ex art. 8.1 LVP-), sin que pueda fundarse la impugnación del deslinde ante este orden jurisdiccional en la sola apreciación de que se desconozcan derechos de propiedad preexistentes, pues en este caso la competencia es de la jurisdicción civil (sin perjuicio, claro está, del posible pronunciamiento prejudicial de los Juzgados y Tribunales de lo contencioso-administrativo en los términos que permite el art. 4 de la LJ$\mathrm{CA})^{33}$.

En relación al procedimiento de deslinde, el art. 8 de la LVP contiene algunas determinaciones básicas y otras de aplicación plena para las Comunidades Autónomas. A la luz de las mismas cabe afirmar que se trata de un acto condicionado por el de clasificación (art. 8.1 y 17 RAVP), a cuyas determinaciones el deslinde añade un estudio posesorio de ocupaciones o intrusiones (dados sus efectos jurídicos) y de colindancias (art. 8.2). En la legislación andaluza, el procedimiento de deslinde está contemplado en los arts. 17 a 23 del RAVP, que prevén las oportunas garantías de publicidad, información pública y participación de los Ayuntamientos en cuyo término radique la vía a deslindar y de las organizaciones y colectivos ecologistas, notificación y audiencia a los colindantes y propietarios afectados; previéndose también la adopción de medidas provisionales por parte de la Administración autonómica (art. 18.5) y la posibilidad de hacer anotaciones marginales preventivas en el Registro Propiedad (art. 8.5 Ley y 19.6 RAVP). Asimismo, el RAVP contempla la tramitación de un procedimiento urgente de deslinde cuando razones de interés público así lo aconsejen (art. 22.1), y otro abreviado para los casos en que exista conformidad entre todos los interesados (art. 22.2).

cia del orden contencioso-administrativo sobre los vicios de los actos dictados y de las actuaciones materiales acordadas en desarrollo de las prerrogativas de protección y defensa patrimonial, así como sobre el control de los motivos del ejercicio de dichas prerrogativas en orden a verificar los hechos determinantes de la decisión administrativa.

\footnotetext{
${ }^{33}$ En este orden de consideraciones, es de consignar que la reiterada Sentencia del Tribunal Superior de Justicia de Andalucía de 22 de diciembre de 2003, llega a afirmar que, pese a la dicción literal del art. 8.6 de la LVP, en aplicación de los principios de economía procesal y unidad del ordenamiento sería posible admitir un recurso contencioso-administrativo contra el deslinde fundado únicamente en la conculcación de un derecho de propiedad preexistente cuando el quebranto al derecho sea "notorio e incontrovertido" (de modo que no necesite pruebas, valoraciones o razonamientos jurídicos) por haber evidencia del mismo en el expediente (por adjuntarse al mismo, v.gr., una sentencia judicial firme, o prueba documental de una transmisión efectuada anteriormente por la Administración), en cuyo caso el orden contencioso-administrativo podría conocer por desviación de poder.
} 
Debe saberse que, a diferencia del procedimiento de clasificación, el de deslinde puede iniciarse a instancia de parte (art. 18.1 del RAVP). No obstante, hay una singularidad en el procedimiento iniciado a instancia de parte que llama poderosamente la atención: en estos casos, el coste del deslinde lo soporta el interesado (art. 18.2 y 3). Previsión que nos parece de dudosa legalidad, habida cuenta que la potestad de deslinde se configura legalmente como un "deber" de la Administración ${ }^{34}$, lo que se compadece mal con la imputación de los gastos que ocasione el ejercicio de la potestad al particular que la excita, por muy interesado que pueda estar en la resolución del deslinde.

Por otra parte, en relación a los expedientes de deslinde que venían tramitándose en nuestra Comunidad antes de la aprobación del RAVP, debe advertirse que la Disposición Transitoria Primera del RAVP previó que "los expedientes relativos a vías pecuarias que se encuentren en tramitación a la entrada en vigor del presente Decreto, adaptarán sus procedimientos a lo previsto en el mismo, sin perjuicio de la conservación de los trámites y actos administrativos ya producidos, computándose los plazos previstos para la resolución de los distintos procedimientos a partir de su entrada en vigor". Esta última previsión permitía la rehabilitación del cómputo de plazos en los expedientes de deslinde (para los que, dado su alto número, perecía pensada la previsión), lo que impedía la alegación del efecto de la caducidad en relación a los deslindes ya iniciados respecto de los que había transcurrido el plazo de resolución (bastante numerosos, por lo demás). Por eso hay que notar que la citada Disposición Transitoria fue justamente anulada por la Sentencia del Tribunal Superior de Justicia de 11 de abril de 2001 (rec. núm. 2251/1998) que, al resolver el recurso contencioso-administrativo directo planteado por ASAJA contra el RAVP, consideró que esta previsión reabría indebidamente el cómputo de plazos de caducidad en contra de lo prevenido en los arts. 43.4 y 48 de la Ley 30/1992, con lo que la mencionada Disposición Transitoria contravenía el principio de jerarquía normativa; pronunciamiento que ha sido

\footnotetext{
${ }^{34}$ Así se deduce de las normas básicas aplicables en la materia: el art. 6.c) de la LPAP habla de "ejercicio diligente de las prerrogativas que la presente ley o otras especiales otorguen a las Administraciones públicas, garantizando su conservación e integridad”, a cuyo fin el art. 28 de la propia Ley añade que "las Administraciones públicas están obligadas a proteger y defender su patrimonio. A tal fin, protegerán adecuadamente los bienes y derechos que lo integran, procurarán su inscripción registral, y ejercerán las potestades administrativas y acciones judiciales que sean procedentes para ello"; por su parte, el art. 3.1.b) de la LVP conmina taxativamente a las Comunidades Autónomas a "ejercer las potestades administrativas en defensa de la integridad de las vías pecuarias".
} 
confirmado por la STS de 15 de noviembre de 2004 (Ar. 7442) que declara no haber lugar al recurso de casación que por tal motivo formuló la Junta de Andalucía contra la citada sentencia del Tribunal Superior de Justicia de Andalucía.

Una vez aprobado el deslinde habrá de procederse al amojonamiento o señalización del terreno, configurado legalmente como la materialización de la realidad física del deslinde (art. 9 LVP), que es el título jurídico que fundamenta el amojonamiento; quedando éste relegado, así, a una simple actividad material que, desde su consideración estrictamente jurídica, equivaldría a la traditio, en la medida en que da efectividad a la toma de posesión. Por consiguiente, la diferenciación entre amojonamiento y deslinde que hace la LVP (cuyo art. 5, al enunciarlas por separado, parece querer singularizar la primera frente a la segunda) es equívoca, ya que el amojonamiento de las vías pecuarias no es sino un mero acto de ejecución del deslinde, que no tiene sustantividad sin aquél. El propio art. 9 de la LVP sienta este carácter subordinado del amojonamiento al definirlo como "el procedimiento administrativo en virtud del cual, una vez aprobado el deslinde, se determinan los límites de la vía pecuaria y se señalizan con carácter permanente sobre el terreno".

El acto de amojonamiento debe notificarse a los interesados (art. 24.4 RAVP). Pero la oposición de los interesados solo cabrá, en consecuencia con la naturaleza material y ejecutoria de esta actividad, en supuestos tasados: fundamentalmente cuando el amojonamiento no esté en línea directa de ejecución con lo declarado en el deslinde o incurra en alguna infracción del ordenamiento independiente del acto que se ejecuta.

Según dispone la LVP, la señalización que plasma el amojonamiento se efectúa mediante hitos o mojones, que cuando se refieran a vías pecuarias de la Red Nacional deberán reflejar dicha circunstancia (art. 18.4 LVP). No obstante, hay una importante singularidad en el procedimiento de amojonamiento que regula el RAVP (arts. 24 a 26), consistente en la previsión de ejecutar un amojonamiento provisional durante el deslinde (que está previsto como suerte de medida cautelar por el art. 19.5 RAVP) y, en todo caso, de considerar el amojonamiento efectivamente producido por su determinación mediante "coordenadas absolutas" (art. 24.1 RAVP), lo que permite concluir que el terreno esta jurídicamente amojonado desde el deslinde (queriendo evitar así, probablemente, los no poco frecuentes episodios de tensión y los altercados que más de una vez se han producido cuando la Administración ha procedido al amojonamiento físico tras el deslinde de bienes públicos). 


\section{Potestades ejecutorias: la recuperación de oficio y el desahucio administra- tivo de vías pecuarias}

Entre las facultades para la defensa de las vías pecuarias de corte ejecutorio o reivindicativo destacan las clásicas potestades de recuperación de oficio o interdictum proprium y la de desahucio administrativo. Nada dice la LVP, sin embargo, sobre estas potestades de defensa demanial, que, no obstante, pueden entenderse comprendidas en la genérica cláusula remisoria de su art. 5.f). Más claramente, la aplicabilidad de estas prerrogativas al ámbito del demanio cañadiego deriva del carácter básico con que las contempla la LPAP que, junto a la potestad de recuperación de oficio de la posesión indebidamente perdida de bienes y derechos tradicionalmente contenida en la legislación patrimonial (art. 55 LPAP) regula con carácter general el régimen de desahucio en vía administrativa de los poseedores de inmuebles demaniales cuando desaparece o decae el título posesorio o las condiciones y circunstancias que amparaban su tenencia (art. 58 LPAP) ${ }^{35}$.

Por su parte, los arts. 27 a 30 del RAVP regulan exhaustivamente la recuperación de oficio de las vías pecuarias, conectando esta potestad al deslinde, del que sería una potestad ejecutoria complementaria. La falta de regulación expresa de la recuperación de oficio en la LVP planteó el problema de la ausencia de cobertura de Ley formal de las previsiones del RAVP en atención a la exigencia constitucional de la reserva de Ley para la imposición de limitaciones o restricciones a la propiedad privada (art. 33 y 53.1, en conexión con el 132.1 de la CE). De hecho, esta alegación fue la base de la argumentación esgrimida por los demandantes en la interposición del recurso contenciosoadministrativo contra el RAVP al que hemos aludido anteriormente. Sin embargo, tanto el Tribunal Superior de Justicia como el Tribunal Supremo rechazaron (en los pronunciamientos antes citados) las pretensiones de los recurrentes en relación a la regulación de la recuperación de oficio, estimando que la aparente falta de cobertura legal de estas y otras disposiciones del RAVP quedaba suficientemente colmada, en el ámbito de nuestra Comunidad, por las previsiones contenidas, con carácter general, en la Ley 4/1986, de 5 de mayo, de Patrimonio de la Comunidad Autónoma de Andalucía (cuyo artículo 21 permite la recuperación de oficio en cualquier momento de los bienes dema-

\footnotetext{
35 Con anterioridad a la LPAP, el desahucio sólo contaba con una regulación general para el ámbito local (art. 120 y ss. RBCL), aparte de las previsiones contenidas en alguna Ley demanial de carácter sectorial (p.ej. art. 108 Ley de Costas) y en la legislación expropiatoria (art. 53 y ss. del REF).
} 
niales que se hallen indebidamente en posesión de terceros y fija los principios generales de actuación para estos supuestos).

Tal y como se desprende de la LPAP ${ }^{36}$, la diferencia entre la potestad de recuperación de oficio y el desahucio reside en la existencia o no de un título administrativo previo que legitime la ocupación. Así, la recuperación de oficio de las vías pecuarias procederá cuando la ocupación posesoria carezca de la oportuna autorización o concesión de uso demanial, lo que permite que la Administración ejerza esta acción interdictal sin necesidad de prejuzgar cuestión alguna de propiedad, de modo que -como tiene declarado la jurisprudencia ${ }^{37}$ , la potestad puede actuar tanto contra el detentador de un bien de titularidad pública constatada como de titularidad presuntamente pública, por lo que su ejercicio no está supeditado al previo deslinde. Ahora bien, en estos casos, la jurisprudencia viene exigiendo la "existencia de una prueba completa y acabada" de la posesión administrativa (el uso público del bien cuestionado), sin perjuicio de su verdadera naturaleza dominical, pues la potestad de recuperación de oficio ciñe sus efectos al estricto ámbito posesorio, sin extenderse a cuestiones de titularidad $^{38}$.

Por su parte, el desahucio procederá cuando haya ocupaciones privativas o autorizaciones de uso especial que impliquen ocupación de la vía pecuaria, ya que presupone la previa declaración administrativa de la caducidad o extinción del título (autorización o concesión) que otorgaba el derecho de utilización (art. 59.1 de la LPAP, en conexión con el art. 93.1 de la LRJAP y PAC -pues el desahucio es una variante de la coacción administrativa-), bien por que acaezca alguna causa de extinción legalmente tipificada o bien porque desaparezcan las circunstancias o condiciones que en su día legitimaron su ocupación por terceros y proceda su rescate o revocación. (art. 100 de la LPAP) ${ }^{39}$.

${ }^{36}$ Para un mayor conocimiento de este régimen puede verse el trabajo de AGIRREAZCUENAGA, I., "La recuperación de la posesión de los bienes y derechos del patrimonio. El desahucio administrativo", en los Comentarios a la Ley 33/2003, de 3 de noviembre, del Patrimonio de las Adminis traciones Públicas, dirigidos por CHINCHILLA MARÍN, C., op. cit., pp. 371 y ss.

37 Vid., por ejemplo, la STS de 4 de enero de 1991 (Ar. 559).

${ }^{38}$ Así, entre otras, SSTS de 20 de octubre de 1980 (Ar. 3920), de 5 de julio de 1991 (Ar. 5792), o de 3 de marzo de 2004 (Ar. 86116).

39 Téngase en cuenta, en este último sentido que, junto al tradicional rescate de concesiones por desaparición de las circunstancias que legitimaron su otorgamiento (con derecho a indemnización), la LPAP ha sentado el principio general de revocación unilateral de las autorizaciones 


\section{POTESTADES DIRIGIDAS A LA ADECUACIÓN (IDONEIDAD Y SUFI- CIENCIA) DEL DOMINIO PÚBLICO CAÑADIEGO}

Analizaremos bajo este epígrafe la serie de potestades administrativas dirigidas a mantener la idoneidad y suficiencia del demanio cañadiego en el sentido de procurar su operatividad o funcionalidad permanente (en los términos que hoy consagra el art. 6.b de la LPAP), que se inspira en la pretensión de racionalizar la constitución y la gestión de los bienes y derechos que integran el dominio público. Esta orientación da sentido a las potestades administrativas que permiten alterar o hacer desaparecer la afectación de las vías pecuarias, modificar su trazado o ampliarlas y restablecerlas. Todas ellas expresan la pretensión del legislador de arbitrar soluciones para conciliar los intereses contrapuestos que históricamente han caracterizado la gestión de estas vías, que si en un tiempo enfrentaron a ganaderos y agricultores, hoy tienen que conciliar la satisfacción de unos usos públicos más variados (no sólo la trashumancia ganadera) con los requerimientos de la ordenación territorial y urbanística y los intereses contrapuestos de los colectivos afectados (a los que, aparte de los ganaderos, agricultores y colindantes, hoy hay que sumar a los grupos ecologistas, a los promotores de turismo rural, etc.)

Debe señalarse preliminarmente que las únicas normas básicas que presiden la regulación legal en este punto son las de la LVP, ya que la regulación que la LPAP hace de este otro tipo de potestades no tiene carácter básico ni son de aplicación plena para las Comunidades Autónomas. Aunque también ha de tenerse en cuenta que, en Andalucía, la norma general es la Ley 4/1986, de 5 de mayo, de Patrimonio (-en adelante LPA- que regula el régimen general de la afectación, desafectación y mutación demanial en el Capítulo III del Título II, arts. 46 a 65), que enmarca las especialidades que contienen los arts. 31 a 45 del RAVP en materia de desafectación y de modificaciones de trazado.

demaniales "por razones de interés público, sin generar derecho a indemnización, cuando resulten incompatibles con las condiciones generales aprobadas con posterioridad, produzcan daños en el dominio público, impidan su utilización para actividades de mayor interés público o menoscaben el uso general" (art. 92.4), consagrando una genérica cláusula a precario para estos títulos de uso que desconoce los supuestos indemnizatorios que tradicionalmente acompañaban la revocación de licencias por motivos de oportunidad o adopción de nuevos criterios de apreciación (art. 16.1 y 3 del RSCL) y que, a nuestro juicio, pone en tela de juicio el principio constitucional de resarcimiento en casos de privación de derechos patrimoniales (art. 33.3 CE). 
1. La desafectación de vías pecuarias como potestad excepcional. Especial consideración de los tramos de vía pecuaria que atraviesen suelo urbano o urbanizable

Como quedó apuntado, la desafectación de vías pecuarias no fue precisa mientras subsistió la posibilidad de clasificar la vía de "innecesaria", ya que una clasificación tal suponía la desafectación implícita de la vía y su paso directo a la condición de bienes enajenables (sin ni siquiera pasar antes la categoría de bienes patrimoniales, como expresamente aclaraba la Exposición de Motivos de la LVP de 1974). Actualmente, y en consonancia con el régimen reforzado de domino público que consagra la vigente legislación de vías pecuarias, el art. 10 de la LVP contempla la potestad de desafectación autonómica en términos excepcionales, estableciendo para ello límites precisos: sólo podrá efectuarse cuando los terrenos de las vías pecuarias no sean "adecuados" para el tránsito pecuario o "susceptibles de los usos" complementarios o compatibles que justifican su naturaleza demanial ${ }^{40}$. Asimismo, se reconoce ahora que "los terrenos ya desafectados o que en lo sucesivo se desafecten tienen la condición de bienes patrimoniales de las Comunidades Autónomas y en su destino prevalecerá el interés público o social”.

En el ámbito de la Comunidad Autónoma andaluza, el art. 60 de la LPA dispone que "la desafectación tendrá lugar cuando un bien de dominio público deje de estar destinado a un uso o servicio público, pasando a ser de dominio privado" 41 . Por su parte, el art. 31 del RAVP subraya la excepcionalidad de esta potestad en relación a las vías pecuarias, estableciendo un presupuesto habilitante específico y determinadas condiciones para su ejercicio, de modo que sólo podrán desafectarse los tramos que hayan perdido los caracteres de su definición y destino como vías pecuarias (de acuerdo con dispuesto en

\footnotetext{
${ }^{40}$ Límites que se convierten en prohibición absoluta en algunas legislaciones autonómicas (como, por ejemplo, en la Ley 9/2003, de 20 de marzo, de vías pecuarias de Castilla y La Mancha), cuando se trate de vías declaradas de interés natural o cultural (aunque, en realidad, esta declaración supone sólo un límite formal adicional: para la desafectación de tales vías será preciso retirar previamente la declaración de interés natural o cultural).

${ }^{41}$ Precisando, en su art. 61 que "La Comunidad Autónoma de Andalucía podrá desafectar bienes de dominio público de que sea titular en las formas previstas para la afectación. Para ello, la Consejería de Hacienda podrá investigar el uso que se haga de los citados bienes. Sin embargo, cuando la afectación haya tenido lugar por Ley, no se entenderá producida la desafectación hasta que la Consejería de Hacienda reciba formalmente el bien y lo incorpore como patrimonial. En cualquier caso, la Comunidad Autónoma de Andalucía deberá proceder a la desafectación cuando los bienes o derechos dejen de estar destinados a usos o servicios públicos”.
} 
los arts. 2 y 4 del RAVP sobre adscripción a los fines que les son propios) y de conformidad con lo que sobre este particular prevea el "Plan Andaluz para la recuperación y ordenación de la red de vías pecuarias de la Comunidad Autónoma de Andalucía”, cuya elaboración preveía la Disposición Adicional Tercera del propio RAVP y que fue aprobado por el Consejo de Gobierno de la Comunidad andaluza mediante Acuerdo de 27 de marzo de $2001^{42}$.

Por lo demás, el citado art. 31 del RAVP regula un procedimiento complejo de desafectación a cargo de la Consejería de Medio Ambiente, que habrá de constatar previamente el uso real de la vía y del tramo considerado y motivar su desafectación fáctica previo trámite de información pública, dándole traslado de la resolución -que ha de publicarse en el BOJA- a la Consejería de Hacienda para que inventaríe del tramo desafectado como bien patrimonial, sin perjuicio de las acciones procedentes contra las posibles usurpaciones de los tramos desafectados.

En relación a estas previsiones autonómicas sobre desafectación de vías pecuarias, debe tenerse en cuenta que la Disposición Adicional del RAVP preveía un supuesto específico para los tramos de vía pecuaria afectados por el planeamiento urbanístico. Dicha Disposición fue objeto de nueva redacción por la Ley autonómica de 17/1999, de 28 de diciembre (de acompañamiento de los presupuestos para 2000), que estableció el régimen de desafectación forzosa de los tramos de vías pecuarias insertas en suelo urbano o urbanizable (en este último caso "siempre que haya adquirido características de suelo urbano") ${ }^{43}$, previendo para ello un procedimiento especial ante la Delegación Provincial de medio ambiente que difiere del procedimiento del art. 31 al que antes nos referíamos y del previsto para las modificaciones de trazado que traigan causa en la aprobación de un nuevo planeamiento territorial o urbanístico a las que se refieren los arts. 39 y 42 del RAVP.

\footnotetext{
42 (BOJA núm. 74, de 30 de junio de 2001), que no contempla previsiones específicas en el sentido de desafectar tramos innecesarios sino que, antes al contrario, está inspirado en un principio claro de conservación y recuperación de la llamada "Red andaluza de vías pecuarias".

${ }^{43}$ Sustancialmente, la redacción actual la Disposición Adicional primera del RAVP difiere de la anterior en que se ha eliminado la excepción que originariamente se hacía respecto de la no desafectación de los tramos de vías pecuarias "que discurran por suelo urbano que carezca de continuidad respecto del núcleo urbano principal y el grado de edificación no sea superior al 50\% respecto a la superficie total del tramo de vía pecuaria afectado".
} 
La previsión de desafectación de las vías pecuarias que se asientan en suelo urbano y urbanizable en los términos que prevé la mencionada Disposición Adicional Primera del RAVP está en lógica conexión con la clasificación de suelo no urbanizable de especial protección que el art. 39.1 del RAVP les da a todas las vías pecuarias; pero que, en todo caso, debe ponerse en conexión con el tratamiento que la Ley $7 / 2002$, de 17 de diciembre, de Ordenación urbanística de Andalucía (LOUA) da a este tipo de bienes.

Con carácter general, y al igual que hace el citado art. 39.1 del RAVP, la LOUA considera las vías pecuarias desde la perspectiva del suelo no urbanizable de especial protección, como implícitamente se desprende del art. 46 LOUA en conexión con el 9.1 de la Ley 6/1998. Sin embargo, creemos que no es incompatible con la LOUA la integración excepcional de estas vías en suelo urbano o urbanizable ${ }^{44}$, pudiendo conservar su condición dentro de estas otras categorías de suelo si se logra que sigan al servicio de alguna de las funciones, distintas al tránsito pecuario, que les son igualmente propias ${ }^{45}$. Para ello caben, en mi opinión, dos posibilidades: $1^{a}$ ) que dichas vías o tramos se ordenen como elementos del "sistema general de comunicaciones" (en el bien entendido que serían comunicaciones agrarias -no automovilísticas y por lo tanto compatibles con el destino demanial de la vía- ${ }^{46}$; o, $2^{\underline{a}}$ ) que se ordenen como elementos del "sistema general de espacios libres", si su uso principal es el medioambiental o el recreativo.

En ambos caso, estaríamos ante sistemas generales ya obtenidos que, por lo tanto, no pueden ser adscritos a efectos de su obtención (salvo que se vayan

\footnotetext{
${ }^{44}$ El propio "Plan Andaluz para la recuperación y ordenación de la red de vías pecuarias de la Comunidad Autónoma de Andalucía" reconoce expresamente que, pese a la desafectación de los tramos de vía pecuaria que transcurran por suelo urbano y urbanizable que se desprende de la Disposición Adicional Segunda del RAVP, dicho tramos "no se excluirán en principio de la red por considerar que los núcleos de población suponen más un nexo de unión que una desconexión para muchos usos de los contemplados en la ley".

${ }^{45}$ Sobre esta cuestión, véase, con carácter general, PORTO REY, E., "Integración de las vías pecuarias en el planeamiento urbanístico”, Revista de Derecho Urbanístico, núm. 126, 1992, pp. 95 a 120; y del mismo autor, en colaboración con FRANCO CASTELLANOS, E., Urbanismo y vías pe cuarias, Cuadernos de Urbanismo, Montecorvo, Madrid, 2000.

46 Pues, como afirma la STS de 22 de abril de 2003 (Ar. 3723) la excepcional integración de un tramo de vía pecuaria en suelo urbano está condicionada, en todo caso, a la especificación mediante la calificación urbanística de un destino legalmente compatible con la naturaleza demanial de la vía.
} 
a crear, en cuyo caso cabe adscribirlos u obtenerlos por expropiación u ocupación directa en marco de una actuación asistematica). Pero de no darse ninguno de estos usos que permiten su integración en estas categorías de suelo, si algún tramo de vía pecuaria quedara incluido en una unidad de ejecución de suelo urbano o urbanizable, la Administración autonómica está obligada a operaciones de mutación demanial o de desafectación a instancias de la Administración actuante (art. 112.1 de la LOUA).

Finalmente, importa destacar que junto a estos supuestos de desafectación expresa vías pecuarias, que puede darse una desafectación implícita derivada de la modificación de su trazado, que, siendo también -como veremosuna potestad excepcional, probablemente sea el supuesto más común de desafectación.

\section{Mutación demanial por cambio de destino}

La mutación demanial por cambio de destino, por la que la Administración titular de un bien de dominio público puede alterar su uso originario mediante su desafectación y simultánea afectación a un uso o servicio público distinto ( $\sin$ cambio de titularidad, pues en ese caso estaríamos ante una mutación subjetiva), no aparece contemplada en la legislación estatal de vías pecuarias ni en la legislación autonómica de desarrollo (tampoco, por lo tanto, en el RAVP). Dado, por lo demás, que la regulación de la LPAP (arts. 71 y 72) no es de aplicación básica ni plena en este punto, las únicas previsiones aplicables a las vías pecuarias andaluzas son las de la LAP (art. 58 y 59), cuya mayor singularidad consiste en la previsión, junto a la mutación demanial expresa, de la posibilidad de mutación demanial "tácita".

No obstante, a tenor de la pluralidad de usos a los que la Ley prevé que puedan destinarse las vías pecuarias aparte de la trashumancia ganadera, para cuya adscripción no sería precisa una mutación o alteración de su destino histórico u originario por caer tales usos en la órbita normal o del destino típico de estas vías (comunicaciones agrarias y usos agrícolas compatibles, así como usos medioambientales, recreativos y culturales complementarios), parece difícil imaginar las necesidades reales del ejercicio de la potestad de mutación de destino más allá, acaso, de las operaciones de mutación demanial que -como veíamos- puedan darse en el contexto de la ejecución urbanística de tramos de vía pecuaria incluidos en suelo urbano o urbanizable que no deban integrarse en estas clases de suelo y seguir manteniendo su destino. 


\section{Modificación del trazado}

La modificación del trazado de una vía pecuaria tiene una doble dimensión jurídica: por un lado, supone la desafectación de los terrenos que abandona el nuevo trazado; por otro lado -y al mismo tiempo-, implica la afectación de las superficies del nuevo itinerario.

La legislación prevé (art. 11 a 13 de la LVP) un supuesto genérico y dos específicos (que cuentan con procedimientos especiales ad hoc en la legislación autonómica de desarrollo):

a) Modificación del trazado por razones de interés público o excepcionales razo nes de interés particular debidamente motivadas

El art. 11.1 de la LVP enuncia este supuesto genérico de desafectación posibilitando que, "por razones de interés público y, excepcionalmente y de forma motivada, por interés particular, previa desafectación, se podrá variar o desviar el trazado de una vía pecuaria, siempre que se asegure el mantenimiento de la integridad superficial, la idoneidad de los itinerarios y de los trazados, junto con la continuidad del tránsito ganadero y de los demás usos compatibles y complementarios con aquél" 47 .

Por lo que se refiere a las condiciones que deben darse para que sea posible una modificación del trazado de la vía pecuaria, la primera es la previa desafectación del tramo de vía pecuaria a modificar, ya sea por causa de interés público o particular. No obstante, estos casos no parece que sea de aplicación la previsión contenida en el art. 10 de la LVP según la cual en el destino de las vías pecuarias desafectadas "prevalecerá el interés público o social". Más bien debe pensarse que en estos supuestos de modificación del trazado el destino que ha de prevalecer es la específica causa que motiva la modificación.

Además de la desafectación, el precepto transcrito establece una condición inexcusable para que sea posible la modificación del trazado: la Administración autonómica tendrá que asegurarse de que el terreno que aporten

\footnotetext{
${ }^{47}$ Es de consignar que alguna normativa autonómica, como la Ley 8/1998, de 15 de junio, de vías pecuarias de la Comunidad de Madrid, ha constreñido aún más el ejercicio de esta potestad discrecional regulando un presupuesto de hecho específico para las modificaciones instadas por interés particular, exigiendo que el mencionado interés particular quede "completamente acreditado" y se acredite igualmente la imposibilidad de satisfacerlo "a través de medios distintos a la modificación del trazado" (art. 23.1).
} 
las Administraciones o los particulares tenga la misma superficie que el terreno de vía pecuaria a modificar, así como comprobar que el nuevo itinerario sea el adecuado para que no se interrumpa el tránsito ganadero y en él se puedan ejercitar el resto de los usos compatibles y complementarios regulados en los artículos 16 y17 de la LVP.

Para los casos en que la modificación del trazado se lleva a cabo a instancia de parte "por razones de interés particular", la normativa autonómica prevé la repercusión de los costes de adquisición y afectación de los nuevos terrenos a los particulares interesados ${ }^{48}$, como hacen los arts. 34.2 y 35.2 del RAVP. A diferencia de lo que dijimos respecto del deslinde de vías pecuarias a instancia de parte, creemos que en este caso la obtención gratuita de los terrenos para la Administración sí está justificada, porque la potestad de modificación no se dirige, en modo alguno, a la defensa de la integridad posesoria de la vía, ni es de obligado ejercicio para la Administración.

El RAVP prevé un "procedimiento general" (art. 33 a 38) por el que han de canalizarse estas modificaciones de trazado que se ajusta a las exigencias básicas de la normativa estatal (el sometimiento del el expediente de modificación a información pública de un mes y a la consulta del Ayuntamiento afectado, así como de las organizaciones profesionales agrarias afectadas y a los colectivos o agrupaciones de ecologistas -art. 11.2 LVP-), añadiendo una serie de previsiones específicas relativas a los actos necesarios para la obtención de terrenos, para los que serían aplicables las normas sobre expropiación, enajenación y permuta de la LAP (art. 38). Aunque, en este sentido, ha de tenerse

\footnotetext{
${ }^{48}$ Así, el art. 23.3 de la Ley 8/1998, de 15 de junio, de vías pecuarias de la Comunidad de Madrid, establece que "la entidad pública o, excepcionalmente y de forma motivada, el sujeto particular, en su caso, cuyo interés motivase el desvío del trazado, habrá de hacerse cargo de los costes que genere el nuevo trazado y facilitar a la Comunidad, con carácter previo los terrenos sobre

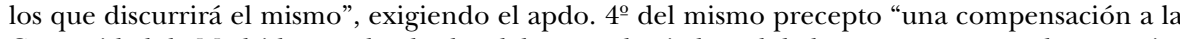
Comunidad de Madrid, cuando el valor del tramo desviado y el de los terrenos aportados no coincidan, aunque tuviesen la misma extensión”. En parecidos términos se expresa el Decreto 3/1998, de 9 de enero, que aprueba el Reglamento de Vías Pecuarias de la Rioja. Por su parte, el art. 12 de la Ley Foral 19/1997, de 15 de diciembre, de vías pecuarias de Navarra, establece que el solicitante de la modificación correrá con los gastos "de trasiego y colocación de mojones del antiguo al nuevo trazado, siguiendo las instrucciones del Departamento de Economía y Hacienda en cuanto al punto y modo de colocación de aquéllos y con sujeción al expediente aprobado". Finalmente, el art. 17 de la Ley 9/2003, de 20 de marzo, de Vías Pecuarias de Castilla-La Mancha, prevé que los particulares que insten las modificaciones de trazado acrediten fehacientemente la titularidad y la plena disponibilidad de los terrenos que ofrecen para el nuevo itinerario, asumiendo los costes de su adquisición.
} 
presente que muchas de las nuevas previsiones de la LPAP sobre adquisición de bienes son de aplicación plena para las Comunidades Autónomas (así lo es, por ejemplo, la regulación de los modos de adquirir del art. 15, la ocupación de bienes a la que se refiere el art. 23 o el régimen de las adquisiciones derivadas del ejercicio de la potestad expropiatoria del art. 24).

b) Modificación del trazado por razones de una nueva ordenación territorio o urbanistica:

Al igual que ocurría para las modificaciones por razón de interés público o particular, el art. 12 de la LVP dispone que en las que deriven de "cualquier forma de ordenación territorial" (entre las que hay que entender comprendida la planificación urbanística), el nuevo trazado "deberá asegurar con carácter previo el mantenimiento de la integridad superficial, la idoneidad de los itinerarios y la continuidad de los trazados, junto con la del tránsito ganadero, así como los demás usos compatibles y complementarios de aquél”. En relación a las modificaciones que traen causa en una reordenación territorial o urbanística, la jurisprudencia ha precisado que aquí en no son exigibles las formalidades que contempla el art. 11 de la LVP para las modificaciones de trazado fundadas en razones de interés público o particular, ya que no las que no exige expresamente el art. 12 de la LVP ni puede decirse que ésta las imponga de modo implícito, pues en estos supuestos la modificación de la vía pecuaria se incardina en un procedimiento más complejo y de garantías mucho más cumplidas, como son los procedimientos de elaboración de los Planes de Ordenación Territorial y los Planes urbanístico (STS de 11 de diciembre de 2002 -Ar. 182 de 2003-).

En este orden de consideraciones, la lacónica previsión del art. 12 de la LVP es completada en el plano procedimental por la legislación autonómica, que establece procedimientos especiales para encauzar esta causa de alteración del trazado ${ }^{49}$. En este contexto normativo destacan las previsiones del RAVP, que dedica los arts. 39 a 42 a regular el procedimiento que ha de seguirse cuando pretende modificarse el trazado de una vía pecuaria como con-

${ }^{49}$ La Ley pionera en la materia fue la Ley Foral 6/1987, de 10 de abril, de Normas Urbanísticas Regionales para la protección y uso del territorio, que arbitró medidas específicas de protección de las vías pecuarias como elementos integrantes de la ordenación territorial (art. 29). Otras disposiciones autonómicas abordan la cuestión desde la perspectiva de las modificaciones de trazado que vienen determinadas por una nueva ordenación territorial, como hacen el Reglamento extremeño de vías pecuarias (arts. 26 a 28), el Reglamento riojano (arts. 33 y 34) o la Ley madrileña de vías pecuarias (art. 26). 
secuencia de la aprobación de un Plan de Ordenación del Territorio, previendo, para el caso de la modificación del trazado por efecto del planeamiento urbanístico, un procedimiento incardinado, en parte, en de evaluación y protección ambiental, en la medida en que la modificación del trazado en estos casos requiere un Estudio de Impacto y una Declaración de Impacto en los términos contemplados en la Ley 7/1994, de Protección Ambiental de Andalucía.

c) Modificación del trazado por la realización de obras públicas y cruces con otras vías de comunicación:

El art. 13.1 prevé que cuando se proyecte una obra pública sobre el terreno por el que discurra una vía pecuaria, la Administración actuante deberá asegurar que el trazado alternativo de la vía pecuaria garantice el mantenimiento de sus características y la continuidad del tránsito ganadero y de su itinerario, así como los demás usos compatibles y complementarios de aquél, precisando en su apdo. $2^{\circ}$ que "en los cruces de las vías pecuarias con líneas férreas o carreteras se deberán habilitar suficientes pasos al mismo o distinto nivel que garanticen el tránsito en condiciones de rapidez y comodidad para los ganados". Este segundo supuesto está limitado en el RAVP a las necesidades del paso (a nivel) que, como ha declarado algún pronunciamiento jurisprudencial, deben satisfacer en todo caso, de forma adecuada, los objetivos enunciados en el apdo. $1^{\circ}$ del art. 13 de la $L V P^{50}$.

$\mathrm{Al}$ igual que sucedía en los supuestos de modificación del trazado derivados de una reordenación urbanística, el art. 44 del RAVP prevé que cuando la obra pública que motiva la modificación esté sometida a una medida de prevención ambiental se siga un procedimiento incardinado en la declaración de impacto o en el informe ambiental pertinente.

Finalmente, debe señalarse que para todos los supuestos de modificación del trazado que hemos analizado, el art. 45 del RAVP establece que la obtención de los terrenos para el establecimiento del trazado alternativo implica su clasificación y deslinde automático, debiendo procederse sólo a su amojonamiento.

\footnotetext{
${ }^{50}$ Es particularmente ilustrativa de las condiciones que han de reunir los pasos alternativos la sentencia del Tribunal Superior de Justicia de Andalucía de 30 de junio de 2005 (rec. apelación núm. 172/2002).
} 
4. Creación, ampliación o restablecimiento de vías pecuarias. La virtualidad de una técnica que toma plena carta de naturaleza tras la aprobación de la LPAP: el establecimiento de servidumbres administrativas de uso público

Las potestades de desafectación y de modificación del trazado resumen las alternativas que la legislación de vías pecuarias ofrece al secular enfrentamiento de intereses contrapuestos en torno al demanio cañadiego. Estas técnicas, inscritas en la dogmática clásica del dominio público, son las principalmente llamadas a resolver los problemas de compatibilidad del destino de las vías pecuarias con las necesidades del uso público y de los intereses particulares. Sin embargo, creemos que las posibilidades que ofrece el ordenamiento en orden a la conciliación de los mencionados intereses no se agotan en el empleo de las técnicas citadas, y que es posible aplicar otra técnica jurídica de alto poder conciliador que no implica, a diferencia de la desafectación de la vía o de la modificación del trazado, la desaparición de la afectación pública: el establecimiento de servidumbres administrativas de uso público concebidas como gravámenes reales que se benefician del régimen tutelar de protección exorbitante que caracteriza la demanialidad y que, en esa medida, son proyección y elemento integrante del dominio público.

La afirmación que acaba de hacerse puede sorprender a quienes, imbuidos de la tradicional creencia de que el dominio público no puede consistir en derechos reales limitados distintos del pleno dominio sobre la cosa (que es la concepción "cosificada" del dominio público que luce en el Código Civil y en la anterior Ley de Patrimonio del Estado), consideran imposible la existencia de iura in re aliena de naturaleza demanial. Pero esta creencia, justificada durante largo tiempo por el Derecho positivo, ha sido desterrada por la nueva LPAP que contempla implícitamente la existencia de servidumbres administrativas de carácter demanial al reconocer como objeto posible del dominio público no sólo a los bienes, sino también los derechos (art. 5), permitiendo así que pueda hablarse con toda propiedad de la existencia de derechos de naturaleza demanial (y, entre ellos, los derechos reales limitados como el de servidumbre).

Quiere decirse, con ello, que la noción de dominio público se concibe con independencia de la cualidad material de las cosas sobre las que recae, pudiendo estar integrado, en consecuencia, por derechos reales limitados distintos al dominio pleno sobre la cosa. En mi opinión, no cabe contrargumentar que ello represente un riesgo de desbordamiento del régimen de la demanialidad, sino, más bien, entender esta previsión legal como una superación de las deficiencias que tenía la dogmática clásica a la hora de explicar los 
fenómenos de disociación entre titularidad y afectación demanial, aparte de representar una apuesta clara por la racionalización del concepto mismo de dominio público, cuyo primer requerimiento es, probablemente, admitir la existencia de regímenes demaniales diversificados en función de los diferentes tipos de bienes o derechos sobre los que la categoría puede proyectase. Aun más, la consideración legal de que el dominio público está formado por bienes o cosas y también por derechos reales limitados, como el de servidumbre, tiene, a la par de un valor ordenador y conceptual, otras utilidades adicionales. En primer lugar, permite aplicar el régimen de protección de la policía y la autotutela demanial a los mencionados derechos limitados de servidumbre que pueden integrar el dominio público (como se deduce de los arts. 6.e y 41 y ss. de la LPAP que reconocen el ejercicio de las potestades de defensa demanial en relación a los "bienes" y "derechos"). Y, en segundo lugar, lo que quizás sea aún más relevante desde un punto de vista práctico, al admitir que las servidumbres administrativas forman parte del dominio público y que son una proyección de éste (de su régimen jurídico) cabe deducir que no siempre es necesario expropiar todo el dominio para conseguir la afectación de un bien a un uso público (con las importantes consecuencias económicas que eso conlleva) sin perder, además, las ventajas de la tutela demanial para proteger dicho uso ${ }^{51}$.

En este orden de consideraciones, debe tenerse en cuenta que el proceso de demanialización que han vivido las vías pecuarias ha afectado en más de un caso a los bienes privados que en algún momento histórico se vieron gravados con servidumbres de uso público. Incluso podría decirse que el engrosamiento progresivo de la demanialidad, que es una constante histórica del Derecho Administrativo, ha tenido uno de sus campos de expansión natural en las propiedades particulares de algún modo afectadas al uso público, lo que ha motivado, en consecuencia, un retroceso paralelo en la aplicación práctica de la figura de las servidumbres administrativas de uso público (no se olvide que el art. 570 del C.C. calificaba expresamente a las vías pecuarias como servidumbres de paso). Sin embargo, como suele suceder cuando la legislación tiende el manto del dominio público sobre una entera categoría de bienes, las excepciones al esquema demanial público no son raras de encontrar (piénse-

\footnotetext{
${ }^{51}$ Sobre todas estas cuestiones y sobra las diversas manifestaciones de la categoría de las servidumbres administrativas entendidas como derechos de naturaleza demanial véase, in extenso, mi monografía sobre Las servidumbres administrativas. Delimitación conceptual, naturaleza, clases y régimen jurídico, Lex Nova, Valladolid, 2003.
} 
se, por ejemplo, en la evolución legislativa en materia de aguas continentales o de costas). No es de extrañar, por tanto, que en estos sectores demanializados pervivan ocasionalmente servidumbres de uso público "marginales" que no han sido alcanzadas por el efecto de fagocitación que el régimen demanial produce sobre los bienes privados antaño afectos servitutis causa a un uso público $^{52}$.

\footnotetext{
${ }^{52}$ Es ejemplo paradigmático de ello, en la órbita de las vías y caminos, la Ley gallega 3/1996, de 10 de mayo, de protección de los Caminos de Santiago, que, tras consagrar que "el camino de Santiago está constituido por vías de dominio público u uso público" (art. 1) que "constituyen bienes de dominio público de carácter cultural" (art. 4), establece expresamente que sobre los tramos del Camino que estén aún en manos privadas "se constituye una servidumbre pública para el paso del Camino sobre propiedad privada de una anchura de tres metros" (art. 2.2), en tanto no se recuperen y adquieran naturaleza demanial; lo que supone la utilización complementaria de la técnica jurídica de la servidumbre personal de uso público que ya contaba con algún precedente en relación al mismo Camino (el Decreto Foral 290/1988, de 14 de diciembre, de delimitación del Camino a su paso por Navarra, dispone que las porciones del Camino que se encuentren en manos privadas serán objeto de expropiación o, en su caso, se establecerán sobre ellas las correspondientes servidumbres de uso público -art. 5-). Este es también el caso de los caminos rurales destinados al servicio de explotaciones agrarias o forestales que en muchos supuestos son objeto de un uso público inveterado para el paso de personas, vehículos o ganado, pese a que, en la inmensa mayoría de los casos, se trata de caminos de propiedad privada protegidos por la tutela posesoria e incluso registral. Como consecuencia de ello, los problemas posesorios que presentan estos caminos ha aflorado invariablemente cuando las Administraciones locales han intentado su recuperación o la tutela demanial de su uso público ante actos obstativos de los propietarios, amparándose en la naturaleza demanial de los caminos que se deduce del art. 79.3 de la LBRL y del art. 3.1 del RBCL. Pero de todos es conocido que frente al titular registral que se opone interdictalmente ante semejante pretensión administrativa, los proclamados dogmas de la imprescriptibilidad y la reipersecutoriedad demanial se desvanecen fácilmente. Esta circunstancia explica que la jurisprudencia haya buscado en muchas ocasiones un término medio, viendo en estos caminos rurales un tipo de bienes singularmente aptos para ser gravados con una servidumbre personal de uso público a favor de los vecinos de la zona (SSTS de 2 de octubre de 1997 -Ar. 7033-, de 5 de enero de 1988 -Ar. 186-, de 13 de junio de 1981 -Ar. 2684-, de 5 de enero de 1971 -Ar. 114- y de 10 de diciembre de 1948 -Ar. 1475-); cosa ante la que ha comenzado a reaccionar una incipiente legislación autonómica que proclama con rotundidad la naturaleza demanial de estos caminos, de la que el mejor exponente es la Ley extremeña 12/2001, de 15 de noviembre, de Caminos Públicos, cuyo art. 6 llega a declarar que "las detentaciones privadas carecerán de valor frente a la titularidad pública, con independencia del tiempo transcurrido". No obstante, teniendo en cuenta los nuevos valores funcionales que hoy están adquiriendo los caminos y rutas de toda índole, parece que la técnica de la servidumbre de uso público podría desempeñar un papel nada despreciable, no sólo ya en este contexto de los caminos rurales, sino también en otros que cobran pujanza como las rutas o itinerarios culturales y turísticos. En este último sentido destaca la Ley balear 13/2000, de 21 de diciembre, del Cami de Cavalls de Menorca (un antiguo vial que circunvala la isla) que, ante la pérdida de su uso militar tradicional y la emergencia de nuevos usos, lo declara sujeto a una "servidumbre pública de tránsito y, en consecuencia, es libre, público, de acceso y utilización gratuitos” (art. 2).
} 
En este sentido, la doctrina ha destacado que ciertos usos públicos que históricamente se han dado en la trashumancia ganadera, instrumentados jurídicamente como servidumbres de paso, han quedado al margen del proceso de demanialización de las vías pecuarias al que nos referíamos ${ }^{53}$, como la jurisprudencia civil ha puesto certeramente de relieve ${ }^{54}$.

A mi juicio, es posible defender la posibilidad de que éstos y otros derechos de paso se articulen técnicamente como servidumbres administrativas de uso público; derechos limitados sobre cosa ajena que, además, gozarían del régimen de protección del dominio público en orden a su delimitación, protección y reivindicación posesoria. Lo que además puede postularse incluso como un uso principal de la categoría, no meramente complementario o marginal, en el contexto de la rehabilitación y restablecimiento de estos caminos o de sus elementos accesorios (majadas, descansaderos, abrevaderos, etc.), cuando sobre los mismos puedan existir derechos de propiedad consolidados. La virtualidad de esta técnica adquiere su mayor potencialidad, así, en relación a las actividades de "creación, ampliación y restablecimiento de las vías pecuarias" a las que se refiere el art. 6 de la LVP (y el art. 10 del RAVP en términos sustancialmente idénticos), que además, precisa que estas actuaciones "llevan aparejadas la declaración de utilidad pública a efectos expropiatorios de los bienes y derechos afectados"; derechos afectados que, como el de servidumbre administrativa de uso público, se obtienen cabalmente por expropiación $^{55}$.

${ }^{53}$ Así, HERRÁIZ SERRANO, O., op. cit., pp. 201 y ss., y 213 y ss.; PONCE SOLÉ, J., op. cit., pp. 70 y ss; y yo mismo, en Las servidumbres... op. cit., pp. 112 y ss., y 188 y ss.

${ }^{54}$ Particularmente, la STS de 10 de noviembre de 1962, que resuelve un caso en el que, frente a la legislación administrativa que ya entonces propugnaba claramente la consideración de las vías pecuarias como dominio público, la Sala $1^{\underline{\underline{a}}}$ del TS acaba decantándose por la naturaleza de servidumbre pecuaria del "Veredón de Morales", que tiene "en cuanto a su acomodación a la clasificación de éstas en prediales y personales, un carácter doble o mixto, ya que es predial en cuanto está establecido a favor de los predios colindantes, y personal en cuanto su uso se extiende también a la comunidad de todos los vecinos de Posadas (Córdoba), según permite el artículo 531 del Código Civil". Desde el punto de vista de la técnica jurídica significa esto que la regulación dada por el Código civil en relación con las servidumbres puede seguir en pie junto a la regulación administrativa que surgió tras ella, e incluso puede prevalecer sobre la misma, tal y como afirmó MARTÍN-RETORTILLO, L., al comentar esta importante sentencia en "El proceso de apropiación por el Estado de las vías pecuarias”, Revista de Administración Pública, núm. 51, 1966, pp. 97 y ss.

${ }^{55}$ Sobre la obtención y valoración expropiatoria de estas servidumbres véase el último Capítulo de mi libro Las servidumbres administrativas...op cit. 


\section{POTESTADES DESTINADAS A GARANTIZAR EL RÉGIMEN DE USOS Y SU CONTROL}

La finalidad de garantía del uso público de las vías pecuarias configura una serie de potestades administrativas y de deberes de los usuarios orientados a la preservación del destino público asignado a las vías y a controlar las desviaciones, tanto con carácter preventivo (régimen de usos) como represivo (potestad sancionadora y resarcimiento de daños).

\section{Tipología de usos y control preventivo de los mismos}

En relación a las técnicas de carácter preventivo, la LVP recoge la posibilidad de restringir ciertos usos y de condicionar los más intensos a la previa obtención de un título administrativo de autorización o concesión para ciertos aprovechamientos y ocupaciones. Como ha quedado dicho, la nueva concepción de las vías pecuarias que adopta la LVP se asienta en la diversidad funcional y la multiplicidad de usos, auténtica piedra de toque para la recuperación de las cañadas para la sociedad en su conjunto. Así, junto al uso principal de estas vías (el tránsito pecuario y agrario), la Ley regula el régimen de los usos compatibles (art. 16), de los usos complementarios (art. 17), de las ocupaciones temporales (art. 14) y de los aprovechamientos sobrantes de las vías pecuarias (art. 15).

Debe señalarse, en este orden de consideraciones, que la nueva LPAP es básica en algunos aspectos relativos al régimen de los títulos de uso (autorizaciones y concesiones demaniales reguladas en los arts. 91 y ss.), y que la legislación autonómica de desarrollo de la LVP ha introducido prohibiciones específicas de usos considerados incompatibles con el destino de estas vías ${ }^{56}$, al tiempo que ha ampliado los supuestos de utilización especial o privativa de las mismas ${ }^{57}$.

\footnotetext{
${ }^{56}$ Entre las que destaca la Ley 8/1998, de 15 de junio, de la Comunidad de Madrid, que prohíbe la caza en todas sus formas, la extracción de rocas, áridos o gravas, los vertidos de cualquier clase, el asfaltado o cualquier procedimiento semejante que desvirtúe su naturaleza, la publicidad (con la única excepción de los paneles de información o interpretación) el tránsito en vehículos todoterreno, motocicleta o cualquier otro vehículo motorizado, y las ocupaciones o instalaciones de cualquier tipo, no autorizadas (art. 43).

${ }^{57}$ Es paradigmática, en este sentido, la Ley 9/2003, de 20 de marzo, de Vías Pecuarias de Castilla-La Mancha, que en sus arts. 22 a 34 regula un exhaustivo régimen de ocupaciones, aprovechamientos y usos compatibles y complementarios de las vías pecuarias.
} 
Por otra parte, en relación a la gestión y control preventivo de usos, cabe decir preliminarmente que llama la atención el escaso y poco relevante papel que tanto la legislación estatal como la autonómica atribuyen a los Ayuntamientos que, aparte de ser los primeros interesados en el destino del suelo, podrían desarrollar una importante tarea de colaboración en este terreno (en mi opinión mucho más propicio que otros -como la defensa demanial o la adecuación del demanio cañadiego- para descargar tareas ejecutivas o promover la colaboración de los Ayuntamientos) ${ }^{58}$. En este sentido, la LVP se limita a prever un trámite de información pública y el informe preceptivo del Ayuntamiento afectado en relación a las ocupaciones temporales (art. 14). No obstante, el RAVP ha querido paliar esta situación de escasez competencial de los Ayuntamientos, y aparte de ciertas previsiones que abundan en su condición de interesados en algunos procedimientos relativos al uso de las vías pecarias $^{59}$, el art. 11 habla de "fórmulas de cooperación con otras Administraciones Públicas y de colaboración con entidades públicas y privadas sin fines lucrativos" para optimizar la gestión y aprovechamiento de estas vías (que, sin embargo -y en buena lógica-, no podrán comprender la facultad de autorización o concesión de ocupaciones y aprovechamientos).

Finalmente, pese a la sistemática legal que diferencia entre usos tradicionales, compatibles y complementarios de las vías pecuarias, el estudio de los usos posibles de las vías pecuarias resulta más claro si se hace conforme a la clasificación tradicional de los usos del dominio público, que es la exégesis adoptada por la doctrina ${ }^{60}$; pudiendo distinguirse, así, entre usos comunes generales, usos comunes especiales y usos privativos de las vías pecuarias.

\section{A) Usos comunes}

Los usos compatibles y los complementarios con el tradicional uso trashumante de las vías, a los que se refieren los arts. 16 y 17 de la LVP son, en puridad, usos comunes generales o especiales. Los primeros no necesitan auto-

\footnotetext{
${ }^{58}$ Sobre las competencias locales en la materia, véase BENSUSAN MARTÍN, P., op. cit., pp. 393 y ss.

${ }^{59}$ Así, el art. 48 del RAVP considera a los Ayuntamientos como interesados en los procedimientos de ocupación temporal, y el art. 58.2 requiere el informe del Ayuntamiento en caso de usos especiales que conlleven la instalación de equipamientos desmontables.

${ }^{60}$ HERRÁIZ SERRANO, O., op. cit., pp. 334 y ss., y ALENZA GARCÍA, J.F., op. cit., pp. 461 y ss.
} 
rización administrativa, pero pueden someterse a ciertas restricciones; los segundos, en cambio, necesitan de una autorización demanial que legitime el uso en virtud del principio de que nadie puede, sin título jurídico que lo autorice, ocupar bienes de dominio público o utilizarlos en forma que exceda el derecho de uso que corresponde a todos (art. 84.1 de la LPAP).

\section{a) Usos comunes generales}

1) El uso propio y prioritario es el tránsito de ganado. Los movimientos de ganado sobre las vías pecuarias son libres y gratuitos (a cuyo fin el paso deberá mantenerse "libre y expedito" de cualquier cerramiento u obstáculo, como precisa el art. 54.3 del RAVP), aunque deberán respetar las disposiciones de la legislación sobre sanidad animal, la normativa de tráfico respecto del tránsito por carreteras en supuestos de cruce con las mismas y lo prevenido -como veremos- en los Planes de Ordenación de los Recursos Naturales cuando transcurran por Parques o Reservas Naturales (Disposición Adicional Tercera de la LVP).

2) Usos compatibles. Se definen como "los usos tradicionales que, siendo de carácter agrícola y no teniendo la naturaleza jurídica de la ocupación, puedan ejercitarse en armonía con el tránsito ganadero" (art. 16.1 LVP). También son libres y prioritarios a los demás usos (art. 1.3 LVP), sólo supeditándose a los requerimientos del tránsito pecuario, lo que explica que alguno de ellos, como las comunicaciones agrarias y las plantaciones, se sometan a ciertas restricciones ${ }^{61}$. En este sentido, el RAVP prevé que los usos compatibles consistentes en plantaciones forestales y la conservación de masas vegetales autóctonas o las comunicaciones agrarias (art. 55) pueden sufrir restricciones cuando obstaculicen el normal tránsito del ganado o pongan en riesgo la protección de ecosistemas sensibles, de las especies protegidas o la protección contra incendios (art. 54.2 RAVP) ${ }^{62}$.

\footnotetext{
${ }^{61}$ Así, las comunicaciones rurales y, en particular, el desplazamiento de vehículos y maquinaria agrícola, deberán respetar la prioridad del paso de los ganados, evitando el desvío de éstos o la interrupción prolongada de su marcha. Por su parte, las plantaciones lineales, cortavientos u ornamentales, sólo se consideran compatibles cuando permitan el tránsito normal de los ganados (art. $16 \mathrm{LVP}$ ).

${ }^{62}$ Estas restricciones habrán de ser establecidas por Orden de la Consejería de Medio Ambiente que, además, podrá prever medidas preventivas adicionales de restricción de usos.
} 
3) Usos complementarios. No se definen exhaustivamente en la LVP, que ofrece una mera relación enunciativa en la que cita el "paseo, la práctica del senderismo, la cabalgada y otras formas de desplazamiento deportivo sobre vehículos no motorizados" (art. 17.1). Además de reproducir estos usos complementarios, el RAVP incide mucho en los de carácter mediambiental, al objeto de poder considerar las vías pecuarias como auténticos "corredores verdes" (citando, en sus arts. 4.2 y 54.1, el fomento de la biodiversidad, el intercambio genético de especies faunísticas y florísticas, la movilidad territorial de la vida salvaje y la mejora y diversidad del paisaje rural). En todo caso, se trata de usos libres que no necesitan autorización previa, aunque -al igual que los usos compatibles antes citados- pueden ser objeto de restricciones temporales en caso de incompatibilidad con determinados factores (entre los que el art. 17.3 de la LVP cita las necesidades de proteger ecosistemas sensibles, masas forestales con alto riesgo de incendio, especies protegidas, o prácticas deportivas tradicionales).

\section{b) Usos comunes especiales sujetos a autorización demanial}

Se trata de usos compatibles o complementarios que, pese a no ser excluyentes de los demás usos, requieren de autorización administrativa (y el eventual pago de una tasa) por la concurrencia de circunstancias especiales de intensidad, peligrosidad o rentabilidad. Debe recordarse, en este punto, que la LPAP ha sentado un principio de libre revocabilidad de estas autorizaciones sin derecho a indemnización (art. 92.4), consagrando así una suerte de cláusula a precario legal que rompe con la regulación tradicional de en la materia y se compadece mal con las previsiones constitucionales sobre el derecho a indemnización derivado de las privaciones de derechos ${ }^{63}$. Los supuestos que se inscriben en esta tipología de uso son:

1) Autorización de circulación de vehículos motorizados que no tengan carácter agrícola, que sólo podrá ser otorgada con carácter excepcional y para uso específico y concreto, sin que pueda serlo en momentos de tránsito pecuario ni para aquellas vías que revistan interés ecológico y cultural (art. 16.1 LVP). La normativa autonómica ha restringido aún más este uso, como hace el art. 55.4 del RAVP (ampliando los casos en que puede prohibirse este uso en función de las circunstancias especiales de ciertas vías). Sin embargo, este mismo precepto precisa que la referida autorización no será requerida para los propietarios y los trabajadores de las parcelas colindantes con la vía pecuaria.

\footnotetext{
${ }^{63}$ Véase el comentario que hacíamos supra, en la nota a pie núm. 39, sobre esta previsión legal.
} 
2) Instalaciones desmontables que se precisen para el desarrollo de ciertos usos complementarios (art. 17.2 LVP). En estos casos, el 58.2 del RAVP prevé un procedimiento especial de autorización que, no obstante, no será de aplicación a la instalación de equipamientos destinados al fomento del uso público de las vías (como pudieran ser los puntos de información a las llamadas "aulas de la naturaleza”).

3) Usos complementarios organizados y colectivos. En desarrollo de las previsiones de la LVP, algunas normas autonómicas han establecido que cuando los usos recreativos y deportivos de las vías pecuarias se realicen de forma colectiva y organizada sea preciso el otorgamiento de una autorización previa. Así lo prevé expresamente el art. 58.2 del RAVP, que en su art. 55.4 añade la exigencia de autorización demanial para el uso de vehículos motorizados no agrícolas. Es igualmente aplicable, en estos casos, el procedimiento autorizatorio especial del art. 58.2 del RAVP al que nos referíamos anteriormente.

Finalmente, cabe añadir que el RAVP contiene una cláusula de cierre para garantizar el control público de los usos que, de algún modo, pudieran mermar u obstaculizar el destino primigenio y prioritario de las vías, de modo que cualquier uso compatible que pudiera representar una alteración de las características de la vía requiere autorización previa (art. 56.1).

\section{B) Usos privativos sujetos a concesión}

Los usos privativos, por su carácter exclusivo y excluyente, se otorgan por concesión. Sobre el régimen jurídico de estas concesiones hay que tener en cuenta algunas previsiones básicas de la LPAP: entre ellas, que su otorgamiento debe hacerse con respeto a los principios de publicidad y concurrencia (art. 93.1 de la LPAP, aunque cabe adjudicación directa en los supuestos del art. 137.4); que han de formalizarse en documento administrativo (que, según el art. 93.2 de la LPAP es título suficiente para su inscripción en el Registro de la Propiedad); que pueden ser gratuitas o sujetas a tasas o precios públicos (cuando hay rendimiento patrimonial o utilidad económica, según precisa el art. 93.4 de la LPAP, cosa que siempre ocurre en los usos privativos previstos en la LVP que, además, prevé que el precio público percibido se aplique a la conservación y vigilancia de la vía); y que no podrán ser titulares de concesiones demaniales las personas en las que concurra alguna de las prohibiciones de contratar reguladas en el Texto Refundido de la Ley de Contratos de las Administraciones Públicas. Por lo demás, la LVP reduce a diez años renovables el plazo máximo de 75 años que para las concesiones demaniales fija la LPAP (art. 93.3). 
La LVP prevé dos supuestos específicos que son puntualmente desarrollados por el RAVP.

1) Ocupaciones temporales. Por razones de interés público y, excepcionalmente y de forma motivada, por razones de interés particular, se podrán autorizar ocupaciones de carácter temporal, siempre que la mismas no alteren el tránsito ganadero ni impidan los demás usos compatibles o complementarios con aquél (art. 14 LVP). En desarrollo de esta previsión, los arts. 46 a 50 del RAVP establecen un procedimiento para el otorgamiento de las concesiones de ocupación temporal.

2) Aprovechamientos sobrantes. Según el art. 15 de la LVP, los frutos y productos no utilizados por el ganado trashumante podrán ser objeto de aprovechamiento privativo, que podrá ser revisado por la Administración cuando se hayan modificado los supuestos determinantes de su otorgamiento y, en caso de fuerza mayor, a petición del interesado (que son las dos causas de extinción especiales que se suman a las que, con carácter general, prevé el art. 100 de la LPAP). Los artículos 51 a 53 del RAVP desarrollan el régimen de los aprovechamientos sobrantes sin introducir innovaciones sustanciales.

\section{Control represivo de usos}

\section{A) Potestad sancionadora}

Siguiendo la sistemática del art. 129.1 de la LRJAP y PAC, el Título IV de la LVP clasifica las infracciones que tipifica en atención al reproche social de la conducta punible, distinguiendo entre infracciones leves, graves y muy graves. La intensidad de la gravedad se modula en función de la incidencia que tenga la actuación infractora sobre los usos de las vías pecuarias y sobre su integridad, siendo más grave la infracción cuanto mayor sea la obstaculización de dichos usos o más perjudicial sea la usurpación (art. 21), lo que tiene lógica correspondencia con las sanciones pecuniarias previstas por la LVP (art. 22), que se impondrán atendiendo a su repercusión en la seguridad de las personas y bienes, así como al impacto ambiental que producen y a las circunstancias del responsable, su grado de culpa, reincidencia, participación, beneficios obtenidos y demás criterios previstos en el art. 131.3 de la LRJPAC (en consonancia con el art. 193.1 de la LPAP).

El régimen sancionador debe cohonestarse con la responsabilidad penal derivada de la comisión de delitos relativos a la Ordenación del Territorio, la 
protección del Patrimonio Histórico y del medio ambiente (arts. 325 y ss. del Código Penal). En este sentido, ha de tenerse presente que la reforma ampliatoria del delito ambiental (Ley Orgánica 15/2003, de 25 de noviembre, de reforma del Código Penal) determina que muchos de los tipos infractores consagrados en la LVP puedan ser considerados hechos delictivos; lo que debe ponerse en conexión con el alcance del principio de non bis in idem y con los efectos interruptivos de las actuaciones penales (art. 23 LVP).

Con independencia de las multas que puedan corresponder en concepto de sanción, es asimismo de destacar la posibilidad de imponer multas coercitivas en relación a la ejecución de aquéllas (art. 19.3 de la LVP), de conformidad con lo dispuesto en el art. 99 de la de la LRJAP y PAC (que no podrán superar el $20 \%$ de la multa fijada por la infracción correspondiente).

Finalmente, respecto a la aplicación de este régimen sancionador hay que consignar el criterio jurisprudencial de exigir como presupuesto de la potestad sancionadora la previa clasificación y deslinde de la vía pecuaria intrusa$\mathrm{da}^{64}$; si bien este presupuesto es sólo exigible cuando la existencia de la vía pecuaria o de sus límites era dudosa ${ }^{65}$.

\section{B) Resarcimiento de daños}

Como es habitual en la legislación sectorial de dominio público, la LVP contempla expresamente, junto a la potestad sancionadora, el deber de resarcimiento de daños causados a las vías pecuarias ${ }^{66}$. Se trata, como es sabido, de una potestad orientada sobre la idea de la restitutio in integrum, de forma que su principal objetivo es lograr la completa restauración de la vía pecuaria al ser y estado anteriores a la agresión mediante el abono de todos los daños y perjuicios causados en la cuantía y plazo que ejecutoriamente establezca el órgano competente para imponer la sanción (art. 20.1 de la LVP en relación con

\footnotetext{
${ }^{64}$ Criterio sentado, entre otras, por las SSTS de 5 de febrero de 1986 (Ar. 1232) y de 22 de noviembre de 1996 (Ar. 8548).

${ }^{65}$ Como precisa la STS de 8 de octubre de 1999 (Ar. 7943).

66 Sobre la configuración y alcance de esta potestad en relación a las vías pecuarias véase HERRÁIZ SERRANO, O., op. cit., pp. 579 y ss. Con carácter general, téngase en cuenta el trabajo de FONT i LLOVET, T., "La protección del dominio público en la formación del Derecho Administrativo español. Potestad sancionadora y resarcimiento de daños”, RAP, núm. 123, 1990, pp. 7 y ss.
} 
el 193.3 de la LPAP); hasta el punto de que cuando no es posible la restauración in natura en el lugar afectado, la LVP prevé una reparación equivalente que permita la recuperación de daño "en otro espacio donde cumpla la finalidad de la vía pecuaria” (art. 20.1), sin perjuicio de la ejecución subsidiaria (art. 20.2.).

A fin de garantizar el cumplimiento de la obligación de reposición, el RAVP prevé que para la concesión administrativa de ocupaciones temporales y de aprovechamientos sobrantes el solicitante haya de formalizar previamente un seguro de cobertura económica por los daños que puedan ocasionarse con motivo de la ocupación (arts. 47.2, 48.3 y 52.3).

\section{LA PROTECGIÓN ADICIONAL DE LAS VÍAS PECUARIAS POR RA- ZONES TERRITORIALES, AMBIENTALES Y CULTURALES}

Como quedó apuntado al principio de este trabajo, el régimen de la intervención administrativa sobre las vías pecuarias ha de completarse con la normativa sectorial que prevé un régimen de protección adicional, como fundamentalmente posibilita la normativa en materia de ordenación del territorio y al urbanismo, de protección ambiental o de protección de los bienes de interés cultural (sin olvidar otras perspectivas, como la turística, que también pudieran proporcionar algún régimen de protección adicional ${ }^{67}$ ).

1) En primer lugar, la ordenación del territorio, en cuanto técnica de coordinación de las diversas actuaciones con incidencia territorial, brinda un instrumento fundamental para la conservación de la red cañadiega. Por ello, la legislación autonómica sobre ordenación del territorio ha sido sensible a la peculiar situación de estas vías, arbitrando técnicas de preservación fundamentalmente orientadas a mantener su integridad superficial cuando la ordenación territorial determina -como vimos- un cambio de trazado de las mismas. En el ámbito andaluz, además, las vías pecuarias son contempladas como uno de los principales elementos lineales de interconexión y cohesión de los espacios naturales contemplados en los Planes de Ordenación del Territorio

\footnotetext{
${ }^{67}$ En este sentido, véase, por todos, el trabajo de ALENZA GARCÍA, J.F., "Turismo y caminos de la naturaleza”, en el libro homenaje al Prof. Eduardo ROCA ROCA, Panorama jurídico de las Ad ministraciones Públicas en el siglo XXI, INAP/BOE, Madrid, 2002, pp. 23 y ss.
} 
que traen causa en la Ley 1/1994, de 11 de enero, de Ordenación del Territorio de Andalucía (art. 9.2 RAVP) ${ }^{68}$.

Mayor virtualidad protectora tiene el planeamiento urbanístico y, en particular, las normas sobre clasificación de suelo, dada la natural vinculación de las vías pecuarias al régimen urbanístico del suelo no urbanizable de especial protección. No obstante, antes hemos advertido que la predisposición de las vías pecuarias a su clasificación como suelo no urbanizable no excluye su eventual inclusión por el planeamiento general en el suelo urbano o urbanizable, pudiendo conservar su condición dentro de estas otras categorías de suelo si se logra, en los términos que veíamos, que sigan al servicio de las funciones que le son propias.

2) Las vías pecuarias reciben asimismo una especial protección por parte de la normativa ambiental en dos supuestos diferenciados que han sido oportunamente analizados por la doctrina ${ }^{69}$. En primer lugar, cuando atraviesan espacios naturales protegidos quedan sometidas al régimen específico del espacio natural de que se trate, como expresamente prevé la Disposición Adicional Tercera de la LVP y ha confirmado la jurisprudencia, al afirmar con rotundidad que "la normativa del Parque Natural y la de los espacios naturales, son prioritarios y prevalecen, sobre las generales de las vías pecuarias" ${ }^{70}$. En segundo lugar, cuando las vías pecuarias son consideradas en sí mismas como espacios naturales también pueden beneficiarse de una protección específica: ya sea mediante su inclusión en alguna de las categorías en el Capítulo II del Título III de la Ley 4/1989, de 27 de marzo, de conservación de los espacios naturales y de la flora y fauna silvestres (particularmente la de "paisaje protegi-

\footnotetext{
${ }^{68}$ La función de las vías pecuarias como corredores ecológicos y elementos lineales de interconexión y cohesión de los espacios naturales desde la perspectiva de la ordenación territorial queda patente en el "Plan para la Recuperación y Ordenación de la red de Vías Pecuarias de la Comunidad Autónoma andaluza” al que ya nos hemos referido en varias ocasiones.

${ }^{69}$ FRANCO CASTELLANOS, C., "El régimen jurídico de los usos ambientales de las vías pecuarias", en El Derecho Administrativo en el umbral del siglo XXI, libro Homenaje al Prof. Martín Mateo, Vol. III, Tirant lo blanch, Valencia, 2001, pp. 3833 y ss.; y ALENZA GARCÍA, J.F., op. cit., pp. 450 y ss.

${ }^{70}$ SSTS de 11 de noviembre de 1997 (Ar. 8455 y 8456) y de 14 de julio de 1998 (Ar. 6780), las tres referidas a la impugnación de la revisión del Plan rector de uso y gestión de Doñana, en las que los recurrentes alegaban la supuesta infracción de la LVP por el Plan fundada en materia de modificación de los usos y pasos de las vías pecuarias y de la competencia para autorizarlos.
} 
do" del art. 17), o de las previstas en la legislación autonómica de espacios naturales; ya por la aplicación de la Directiva 92/43/CEE, de 21 de mayo, relativa a la conservación de los hábitats naturales y de la fauna y flora silvestres, uno de cuyos objetivos es la creación de una Red de espacios naturales significativos a nivel europeo (la llamada Red Natura), en la que pueden integrarse "aquellos elementos que, por su estructura lineal y continua o por su papel de puntos de enlace resultan esenciales para la migración, la distribución geográfica y el intercambio genético de las especies silvestres" (art. 10). Condiciones que cumplen plenamente las vías pecuarias, como reconoció el art. 7 del R.D. 1997/1995, de 7 de diciembre, por el que se establecen medidas para contribuir a garantizar la biodiversidad, y como, para el ámbito de Andalucía, también reconoce expresamente el Plan para la Recuperación y Ordenación de la red de Vías Pecuarias aprobado por Acuerdo del Consejo de Gobierno andaluz de 27 de marzo de 2001.

3) Finalmente, las características morfológicas de las vías pecuarias, en las que naturaleza y cultura están fuertemente imbricadas, predisponen singularmente a estos caminos para su utilización con fines de turismo cultural y educativo. La relevancia cultural de las vías pecuarias ha motivado que algún autor haya postulado su inclusión en el Patrimonio Histórico, en orden a su protección como tal, mediante su genérica declaración como Conjunto o "Camino" Histórico -siguiendo el ejemplo del Camino de Santiago- ${ }^{71}$. No obstante, hay quién señala las dificultades jurídicas para lograr dicha declaración respecto de toda la red de vías pecuarias (que, por ejemplo, no parecen tener la "unidad de asentamiento" que demanda la LPHA para Conjuntos Históricos art.15-), por lo que, más moderada y específicamente, circunscriben las posibilidades protectoras que brinda la legislación de Patrimonio Histórico, tanto estatal como autonómica, a aquellas vías pecuarias o tramos de ellas claramente identificados en los que se acredite la existencia de un auténtico interés histórico-cultural ${ }^{72}$.

En este orden de consideraciones, debe tenerse en cuenta que algunas leyes autonómicas sobre vías pecuarias (como la madrileña y la castellano-manchega) prevén expresamente la posibilidad de que estas vías sean declaradas

\footnotetext{
${ }^{71}$ Véase HERRÁIZ SERRANO, O., "Algunas consideraciones críticas en torno a la eventual clasificación de las vías pecuarias como patrimonio cultural”, Revista Aragonesa de Administración Pú blica, núm. 12, 1998, p. 244.

72 ALENZA GARCÍA, J.F., Vias pecuarias, op. cit., p. 459.
} 
bienes de interés cultural, sin que dicha calificación suponga -sin embargo- un cambio sustancial de las normas generales de protección, más allá de algunas medidas protectoras adicionales y de una regulación específica del régimen de usos compatibles ${ }^{73}$. No obstante, la posibilidad abierta por estas leyes autonómicas determina la remisión a la legislación sobre patrimonio-histórico de cada Comunidad Autónoma considerada, en la medida en que esta legislación pueda brindar un régimen específico de protección a las vías pecuarias cuando sean susceptibles de encajar en alguna de las categorías protectoras incluidas en esa genérica declaración de bien de interés cultural ${ }^{74}$.

\footnotetext{
${ }^{73}$ Medidas específicas de protección consistentes, por ejemplo, en la imposibilidad de desafectación de las vías pecuarias calificadas de interés cultural, o en la adopción de medidas cautelares frente a las ocupaciones no autorizadas, como las que contempla la Ley castellano-manchega.

${ }^{74}$ En el caso de Castilla-La Mancha, la Ley 4/1990 del Patrimonio Histórico no establece categorías de protección propias, por lo que habrá de estarse a las de la Ley estatal. Atendiendo a las definiciones que ésta ofrece de los Monumentos, Jardines Históricos, Conjuntos Históricos, Sitios Históricos y Zonas arqueológicas, se verá que sólo de manera muy forzada las vías pecuarias podrían encajar en el concepto de Sitio Histórico, definido como el "lugar o paraje natural vinculado a acontecimientos o recuerdos del pasado, a tradiciones populares, creaciones culturales o de la naturaleza y a obras del hombre, que posean valor histórico, etnológico, paleontológico o antropológico" (art. 15). Por su parte, la Ley madrileña 10/1998 de Patrimonio Histórico sí define diferentes categorías de bienes de interés cultural (art. 9.2), añadiendo a las estatales la de "lugar de interés etnográfico", que define como "el paraje natural susceptible de delimitación espacial o conjunto de construcciones o instalaciones vinculadas a las formas de vida, cultura, costumbres, acontecimientos históricos y actividades tradicionales significativas del pueblo madrileño o de los lugares que, dentro del ámbito territorial de la Comunidad de Madrid merezcan ser preservados por su interés etnológico". En la medida en que se le logre acreditar el valor etnológico de una vía pecuaria podría inscribirse en esta categoría, como, en su caso, podría hacerse en la de Sitio Histórico si, por el contrario, se estima que constituye un lugar, en términos del art. 9.2. d) de la Ley madrileña, "vinculado a acontecimiento o tradiciones del pasado, creaciones culturales o de la naturaleza, y a obras del hombre que posean valores históricos, artísticos o técnicos".
} 